\title{
Accuracy Assessment of Nonlinear Seismic Displacement Demand Predicted by Simplified Methods for the Plateau Range of Design Response Spectra
}

\author{
Pierino Lestuzzi $\mathbb{D}^{1}$ and Lorenzo Diana ${ }^{1,2}$ \\ ${ }^{1}$ EPFL-ENAC-IIC-IMAC, Lausanne, Switzerland \\ ${ }^{2}$ DICEA, Università degli studi di Napoli Federico II, Naples, Italy \\ Correspondence should be addressed to Pierino Lestuzzi; pierino.lestuzzi@epfl.ch
}

Received 28 February 2019; Accepted 9 August 2019; Published 19 September 2019

Guest Editor: Francisco López Almansa

Copyright (c) 2019 Pierino Lestuzzi and Lorenzo Diana. This is an open access article distributed under the Creative Commons Attribution License, which permits unrestricted use, distribution, and reproduction in any medium, provided the original work is properly cited.

\begin{abstract}
The nonlinear seismic displacement demand prediction for low-period structures, i.e., with an initial fundamental period situated in the plateau of design response spectra, is studied. In Eurocode 8, the computation of seismic displacement demands is essentially based on a simplified method called the N2 method. Alternative approaches using linear computation with increased damping ratio are common in other parts of the world. The accuracy of three methods for seismic displacement demand prediction is carefully examined for the plateau range of Type- 1 soil class response spectra of Eurocode 8 . The accuracy is assessed through comparing the displacement demand computed using nonlinear time-history analysis (NLTHA) with predictions using simplified methods. The N2 method, a recently proposed optimization of the N2 method, and the Lin and Miranda method are compared. Nonlinear single-degree-of-freedom systems are subjected to several sets of recorded earthquakes that are modified to match design response spectra prescribed by Eurocode 8. The shape of Eurocode 8 response spectra after the plateau is defined by a constant pseudovelocity range $(1 / T)$. However, the slope of this declining branch may be specified using precise spectral microzonation investigation. However, the $\mathrm{N} 2$ method has been found to be particularly inaccurate with certain microzonation response spectra that are characterized by a gently decreasing branch after the plateau. The present study investigates the impact of the slope of the decreasing branch after the plateau of response spectra on the accuracy of displacement demand predictions. The results show that the accuracy domain of the $\mathrm{N} 2$ method is restricted to strength reduction factor values around 3.5. Using the N2 method to predict displacement demands leads to significant overestimations for strength reduction factors smaller than 2.5 and to significant underestimations for strength reduction factors larger than 4. Fortunately, the optimized N2 method leads to accurate results for the whole range of strength reduction factors. For small values of strength reduction factors, up to 2.5 , the optimized N2 method and the Lin and Miranda method both provide accurate displacement demand predictions. However, the accuracy of displacement demand prediction strongly depends on the shape of the response spectrum after the plateau. A gently decreasing branch after the plateau affects the accuracy of displacement demand predictions. A threshold value of 0.75 for the exponent of the decreasing branch $\left(1 / T^{\alpha}\right)$ after the plateau is proposed. This issue should be considered for the ongoing developments of Eurocode 8.
\end{abstract}

\section{Introduction}

Structures do not remain elastic under extreme ground motions. Nonlinear behavior is therefore crucial in seismic response of structures. However, to avoid the use of more elaborated analyses that are suitable for strategic buildings only, structural-engineering approaches are generally based on simplified methods to determine seismic actions. The prediction of nonlinear seismic demand using linear elastic behavior for the determination of peak nonlinear response is widely used for seismic design as well as for vulnerability assessment. Existing methods involve either a linear 
response based on initial period and damping ratio, eventually corrected with factors, or a linear response based on increased equivalent period and damping ratio.

It is well established that for medium-to-high period structures, the displacements of elastic and inelastic systems are approximately the same. This empirical finding known as the equal displacement rule (EDR) is nowadays widely used for seismic design purposes, e.g., in Eurocode 8 [1]. The basic assumption of the EDR is to predict the seismic performance of an inelastic system using the equivalent elastic system with the same initial period and damping coefficient. For lowperiod structures, the EDR loses its validity, since inelastic displacements are larger than elastic displacements. Other methods are therefore needed for this range of periods. The plateau range of the design spectra is particularly important since it provides the highest spectral acceleration. Furthermore, most buildings in Europe have less than 5 stories and thus have a natural period of less than $1 \mathrm{~s}$. As a consequence, the natural period of a large part of the European building stock is located on the plateau of design spectra, i.e., out of the assumed standard range of application of the EDR. Reliable displacement demand predictions are therefore crucial for seismic vulnerability assessment of existing buildings. This is a key issue in vulnerability assessment at urban scale, where such displacement demand predictions are used for determining building damage using mechanical methods [2]. On the plateau of design spectra, Riddell et al. [3] and later Vidic et al. [4] proposed to compute the displacement demand based on a linear variation of the strength reduction factor as a function of the period. Alternative methods using equivalent damping approaches [5] were also developed and included in the design code in the US $[6,7]$.

The N2 method developed by Fajfar [8] is based on the equal displacement rule associated to a correction for the plateau range of the response spectrum. A simplified version of the N2 method was proposed in Eurocode $8[1,8]$. This simplified version of the N2 method is investigated in this study. However, the lack of accuracy of the simplified version of the N2 method especially for low-period structures has already been pointed out by several research studies $[9,10]$. In case of high-strength reduction factors, the simplified N2 method leads to unconservative results, since displacement demand predictions are underestimated with respect to nonlinear time-history analysis. By contrast, in case of low-strength reduction factors, displacement demand tends to be overestimated when using the simplified N2 method. Therefore, an optimized version of the simplified N2 method has recently been proposed in order to improve the reliability of displacement demand predictions [11]. The objective of this paper is to investigate the accuracy domain of the simplified N2 method and that of the optimized N2 method for displacement demand prediction in the plateau range of seismic design spectra. For comparison, the Lin and Miranda [5] method using equivalent period and damping ratio approaches is also investigated. The accuracy assessment is based on a comparison of the displacement demand computed using nonlinear time-history analysis (NLTHA) with the ones predicted by the three simplified methods.

\section{Seismic Displacement Demand Prediction}

The simplified version of the N2 method (according to Eurocode 8 and called "N2 method" in the following for simplicity), an optimized version of the simplified N2 method and the Lin and Miranda method are investigated in this study. These methods are briefly described in the following sections.

2.1. N2 Method. Since Veletsos and Newmark [12], it has been widely acknowledged that the displacements of elastic and inelastic systems are approximatively the same (Equal Displacement Rule, EDR). This empirical rule was confirmed by numerous numerical and experimental investigations (e.g., [13]) except for low-period structures, for which inelastic displacements are higher than elastic displacements. Another method is therefore needed to replace the EDR for the plateau period range, where EDR is no longer valid. The basic assumption of the EDR is to model an inelastic system using the equivalent elastic system with the same period and the same damping ratio. As illustrated in Figure 1(a), the EDR states that inelastic peak displacements $\left(y_{\mathrm{p}}\right)$ are approximately equal to elastic peak displacements $\left(y_{\mathrm{el}}\right)$ whatever the selected yield strength $\left(F_{y}=F_{\mathrm{el}} / R\right.$ or yield displacement $\left.y_{y}=y_{\mathrm{el}} / R\right)$ of the structure. Note that when assuming the stiffness to be independent of the strength, the EDR leads to a strength reduction factor $(R)$ equal to the global displacement ductility.

On the plateau period range of design spectra, Riddell et al. [3] and later Vidic et al. [4] proposed a linear variation of the strength reduction factor $(R)$ as a function of the period $(T)$ for a constant displacement ductility demand $(\mu)$, later used in EC8:

$$
R=1+(\mu-1) \frac{T}{T_{0}} .
$$

In this assumption, the strength reduction factor $(R)$ varies between 1 for a zero period and the value of the displacement ductility demand for the period $T_{0}$ being close to the end of the plateau, $T_{C}$. Based on equation (1), Fajfar has introduced the $\mathrm{N} 2$ method [8] by considering two domains, separated by the period $T_{0}$. Eurocode 8 includes a simplified version of the N2 method where the displacement demand is determined as follows:

$$
\begin{cases}S_{\mathrm{d}}=\frac{S_{\mathrm{de}}}{R_{\mu}} \cdot\left[\left(R_{\mu}-1\right) \cdot \frac{T_{\mathrm{C}}}{T}+1\right], & T<T_{\mathrm{C}} \text { and } R_{\mu}>1, \\ S_{\mathrm{d}}=S_{\mathrm{de}}, & T \geq T_{\mathrm{C}} \text { or } R_{\mu} \leq 1,\end{cases}
$$

where the parameters $T_{\mathrm{C}}, S_{\mathrm{de}}$, and $S_{\mathrm{ae}}$ are the corner period limiting the zone of the spectrum of maximum acceleration (i.e., plateau), the spectral displacement of the structure with an unlimited elastic behavior and the elastic spectral acceleration, respectively. These parameters define the seismic displacement demand $\left(S_{\mathrm{d}}\right)$. The period $T$ (period of vibration of the structure) and the strength reduction factor $R_{\mu}$ 


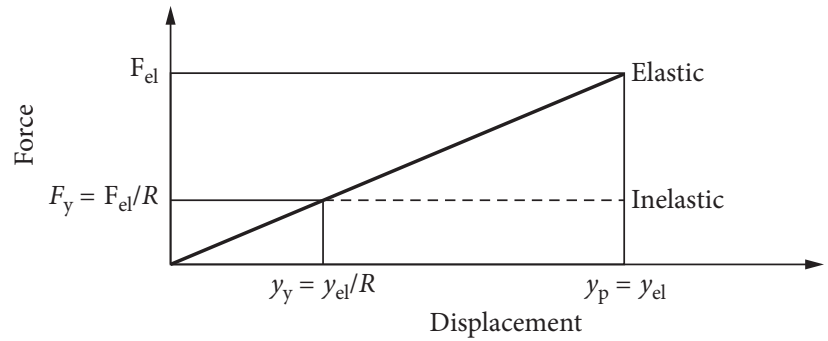

(a)
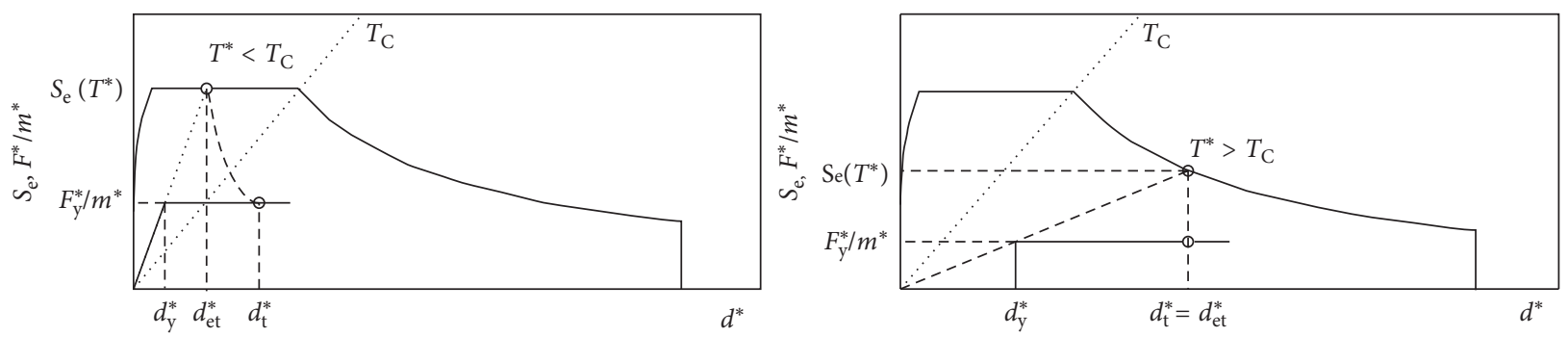

(b)

FIGURE 1: (a) Schematic description of the equal displacement rule (EDR). (b) ADRS representation of the nonlinear displacement demand according to EC8 (adapted from [1]).

$\left(R_{\mu}=S_{\mathrm{ae}} / S_{\mathrm{ay}}\right)$ are parameters defining building capacity. The value $S_{\text {ay }}$ represents the yield acceleration of the structure.

2.2. Optimized N2 Method. The second method that is evaluated has been proposed by Diana et al. [11] and is based on an optimization of the original N2 method. An exponent correction to the classical N2 formulation has also been proposed by Graziotti et al. in 2014 [14], based on shakingtable tests; however, the correction is valid exclusively for stiff masonry structures. The proposal by Diana et al. [11] enhances the N2 method to include an additional exponent and multiplicative coefficients for correction. The new formula has been obtained by a global optimization metaheuristic employing a genetic algorithm to minimize differences between the formula and the NLTHA. The approach of the optimized N2 method preserves the mathematical compatibility with the previous N2 method. The formula is defined starting from (2), including three coefficients, as follows:

$$
\begin{cases}S_{\mathrm{d}}=\frac{S_{\mathrm{de}}}{R_{\mu} / 1.48} \cdot\left[\left(\frac{R_{\mu}}{1.45}-1\right)^{1.35} \cdot \frac{T_{\mathrm{C}}}{T}+1\right], & T<T_{\mathrm{C}} \text { and } R_{\mu}>1, \\ S_{\mathrm{d}}=S_{\mathrm{de}}, & T \geq T_{\mathrm{C}} \text { or } R_{\mu} \leq 1 .\end{cases}
$$

At the end of the plateau, for periods close to $T_{C}$, the nonlinear displacement demand according to (3) may lead to values that diverge notably from the EDR. The compatibility with EDR in $T_{\mathrm{C}}$ is nevertheless necessary because EDR is valid after the plateau of the design spectrum, according to EC8. This drawback does not appear with the N2 method (see equation (2)). This is due to the introduction of three coefficients in (3). In order to avoid such a discrepancy in the period range at the end of the plateau of the response spectrum (i.e., for periods close to $T_{C}$ ), the displacement demand is limited by an additional condition based on a relationship proposed by Michel et al. [10]. Figure 2 shows the relationship (proposition 2) which corresponds to a linear variation of the displacement demand with respect to the period $(T)$. The prolongation of the EDR for the period range of the plateau corresponds to a linear variation (proposition 1 in Figure 2). Proposition 2 keeps the linear variation but with an initial value of one third of the spectral displacement at the end of the plateau. This linear relationship (proposition 2) was found to lead to adequate upper bound values of the displacement demand for large values of strength reduction factors [10]. According to proposition 2, the displacement demand is computed as follows:

$$
S_{\mathrm{d}}=S_{\mathrm{d}}\left(T_{\mathrm{C}}\right) \cdot\left[\frac{T}{T_{C}} \cdot \frac{2}{3}+\frac{1}{3}\right] .
$$

With the optimized N2 method, the smaller value of (3) and (4) is considered as the displacement demand prediction for the period range of the plateau of the corresponding design spectrum (between $T_{\mathrm{B}}$ and $T_{\mathrm{C}}$ ).

2.3. Lin and Miranda Method. The Lin and Miranda method (2008) is based on equivalent linearization. The displacement demand of a nonlinear single-degree-of-freedom (SDOF) system is calculated considering the displacement demand of an equivalent linear-elastic SDOF system having a period and a damping ratio higher than those of the initial nonlinear system [7]. Therefore, the inelastic displacement demand of the nonlinear SDOF system is determined as 


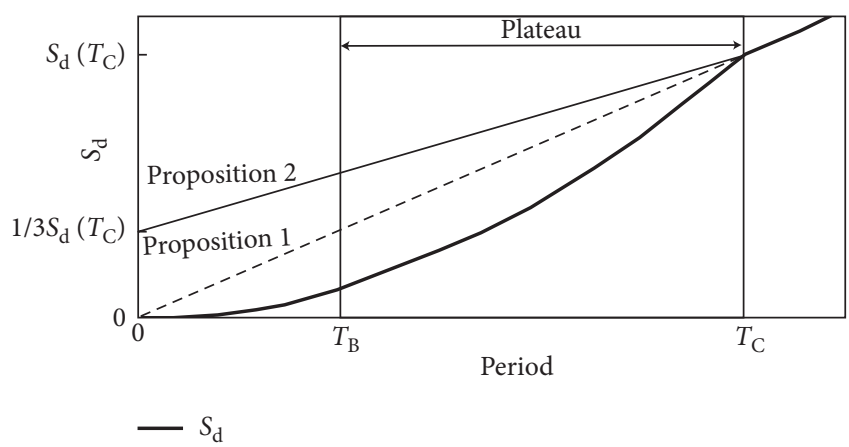

Figure 2: A linear relationship of the displacement demand with respect to the period (proposition 2) is used as a limitation of the displacement demand prediction in the period range close to the end of the plateau (i.e., for periods shorter but close to $T_{C}$ ) [10].

$$
S_{\mathrm{d}}=S_{\mathrm{d}}\left(T_{\mathrm{eq}} ; \xi_{\mathrm{eq}}\right)=S_{\mathrm{d}}\left(T_{\mathrm{eq}} ; \xi_{=5 \%}\right) \cdot \eta=S_{\mathrm{a}}\left(T_{\mathrm{eq}} ; \xi_{=5 \%}\right) \cdot \frac{T_{\mathrm{eq}}^{2}}{4 \pi^{2}} \cdot \eta \text {, }
$$

where $S_{\mathrm{d}}\left(T_{\mathrm{eq}} ; \xi_{\mathrm{eq}}\right)$ is the spectral displacement demand of the equivalent system, $T_{\mathrm{eq}}$ is the equivalent period of vibration of the equivalent system; $\xi_{\mathrm{eq}}$ is the equivalent viscous damping ratio, $S_{\mathrm{d}}\left(T_{\mathrm{eq}} ; \xi_{=5 \%}\right)$ is the displacement demand of the linear system with $5 \%$ damping elastic ratio, and $\eta$ is a reduction factor depending from the damping ratio $\xi$. The reduction factor $\eta$ can be determined as (numerical value to be used for $\xi_{\text {eq }}$, not in “\%”)

$$
\eta=\sqrt{\frac{1}{0.5+10 \xi_{\mathrm{eq}}}}
$$

The equivalent period $T_{\text {eq }}$ and the equivalent damping ratio $\xi_{\text {eq }}$ depend on the strength reduction factor $R_{\mu}$ of the nonlinear SDOF system and on the initial period of vibration and damping ratio, respectively. Several equivalent linear methods exist in literature that differ mainly for the functions used to compute $T_{\text {eq }}$ and $\xi_{\text {eq }}$ (e.g., Iwan [15]; Miranda and Ruiz-García [16]; Sullivan et al. [17]).

In their work (2008), Lin and Miranda give the equivalent period and the equivalent damping ratio as follows:

$$
\begin{aligned}
& T_{\text {eq }}=\left[1+\frac{m_{1}}{T^{m 2}} \cdot\left(R_{\mu}{ }^{1.8}-1\right)\right] \cdot T, \\
& \xi_{\text {eq }}=\xi_{=5 \%}+\frac{n_{1}}{T^{n_{2}}} \cdot\left(R_{\mu}-1\right) .
\end{aligned}
$$

Coefficients $m_{1}, m_{2}, n_{1}$, and $n_{2}$ depend on the postyield stiffness ratio $\alpha$ (Table 1 ), $R_{\mu}$ and $T$ are, respectively, the strength reduction factor and the initial period of vibration of the nonlinear SDOF and $\xi_{=5 \%}$ is the 5\% damping elastic ratio.

\section{NLTHA Methodology}

The methodology used in this study for the nonlinear timehistory analysis (NLTHA) is similar to the one proposed in previous investigations [2, 10]. Nonlinear responses of SDOF systems exposed to acceleration time-histories are
TABle 1: Coefficients for calculating equivalent period and damping [18].

\begin{tabular}{lcccc}
\hline$\alpha(\%)$ & $m_{1}$ & $m_{2}$ & $n_{1}$ & $n_{2}$ \\
\hline 0 & 0.026 & 0.87 & 0.016 & 0.84 \\
5 & 0.027 & 0.65 & 0.027 & 0.55 \\
10 & 0.027 & 0.51 & 0.031 & 0.39 \\
20 & 0.024 & 0.36 & 0.030 & 0.24 \\
\hline
\end{tabular}

computed and the difference between the obtained peak displacement demands and those predicted by the various simplified methods is calculated. The nonlinear structural behavior is described by the popular modified Takeda hysteretic model. For each design spectrum, a set of 12 recordings is first selected from a database, such as the European Strong Motion Database [19], and slightly modified to match the corresponding response spectrum.

3.1. Design Response Spectra. Response spectra according to the soil classes of Eurocode 8 [1] are tested in this study. More specifically, soil classes A, B, C, and D are used. The values of the parameters for the Type 1 defined by EC8 are shown in Figure 3. The values of the corner periods $T_{B}$ to $T_{C}$ delimiting the plateau region of response spectra depend on soil classes. The shape after the plateau is defined by a constant pseudovelocity range $\left(1 / T\right.$, from corner period $T_{\mathrm{C}}$ to period $T_{\mathrm{D}}$ ) followed by a constant relative displacement range $\left(1 / T^{2}\right.$ after $\left.T_{\mathrm{D}}\right)$. Additionally, some response spectra resulting from spectral microzonation studies in Switzerland are also considered in the analysis. Microzone response spectra considered in this study are those of the towns of Yverdon, Sion, and Martigny. In detail, microzone spectra considered are S2, S3, and S4 for Yverdon, A1, A2, and A3 for Sion, and M3 for Martigny. The response spectra specified for the considered microzones in Yverdon [20] are plotted in Figure 3. Figure 4 shows the response spectra specified for the six microzones in Sion and Martigny ([21]).

The plateau acceleration level of the response spectrum for microzone S2 is higher and that for microzone S4 is lower than the ones of EC8. Furthermore, the shapes after the plateau diverge from the ones of EC8 response spectra. The response spectrum for microzone $\mathrm{S} 2$ has an exponent of the declining branch after the plateau of $\alpha=1.6$ and that for microzone S4 has an exponent of $\alpha=0.74$. The response spectrum for microzones S3 and S3 mod has a shape that is compatible with EC8, which is characterized by a constant pseudovelocity range $(1 / T)$ after the plateau.

The plateau acceleration level of the response spectra of microzones A1, A2, and A3 corresponds to the one of EC8 soil class A, C, and D respectively. However, plateau corners of the response spectra of microzones A1 and A2 are modified towards higher periods. These modifications are related to increased seismic demands with respect to the ones of corresponding soil classes defined in EC8. Plateau acceleration levels of the response spectra of microzones M1 and M3 of Martigny are higher than those of Sion. The response spectrum of microzone $\mathrm{M} 1$ is huge and thus related to a larger seismic demand. Except for the low-period range, 

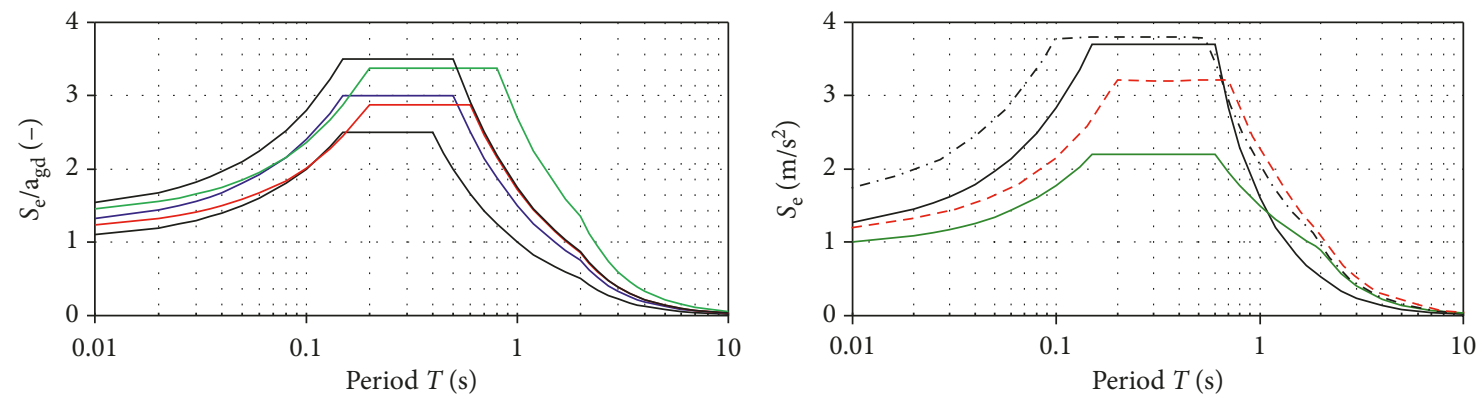

$\begin{array}{ll}\text { S Soil class A } & \text { Soil class D } \\ \text { Soil class B } & \text { Soil class E } \\ \text { Soil class C } & \\ \text { Soil class A: } & \text { Soil class B: } \\ S=1.0(-) & S=1.2(-) \\ T_{\mathrm{B}}=0.15(\mathrm{~s}) & T_{\mathrm{B}}=0.15(\mathrm{~s}) \\ T_{\mathrm{C}}=0.40(\mathrm{~s}) & T_{\mathrm{C}}=0.50(\mathrm{~s}) \\ T_{\mathrm{D}}=2.00(\mathrm{~s}) & T_{\mathrm{D}}=2.00(\mathrm{~s}) \\ & \\ \text { Microzone S2: } & \text { Microzone S3: } \\ S_{\mathrm{e}, \max }=3.7\left(\mathrm{~m} / \mathrm{s}^{2}\right) & S_{\mathrm{e}, \max }=3.2\left(\mathrm{~m} / \mathrm{s}^{2}\right) \\ T_{\mathrm{B}}=0.15(\mathrm{~s}) & T_{\mathrm{B}}=0.20(\mathrm{~s}) \\ T_{\mathrm{C}}=0.60(\mathrm{~s}) & T_{\mathrm{C}}=0.70(\mathrm{~s}) \\ T_{\mathrm{D}}=2.00(\mathrm{~s}) & T_{\mathrm{D}}=2.00(\mathrm{~s})\end{array}$

\begin{tabular}{|c|c|}
\hline $\begin{array}{ll}- & \text { Microzone S2 } \\
-- & \text { Microzone S3 }\end{array}$ & $\begin{array}{ll}\text { _- Microzone S4 } \\
\text { Microzone S3 mod }\end{array}$ \\
\hline $\begin{array}{l}\text { Soil class C: } \\
S=1.15(-) \\
T_{B}=0.20(\mathrm{~s}) \\
T_{\mathrm{C}}=0.60(\mathrm{~s}) \\
T_{\mathrm{D}}=2.00(\mathrm{~s})\end{array}$ & $\begin{array}{l}\text { Soil class D: } \\
S=1.35(-) \\
T_{B}=0.20(\mathrm{~s}) \\
T_{\mathrm{C}}=0.80(\mathrm{~s}) \\
T_{\mathrm{D}}=2.00(\mathrm{~s})\end{array}$ \\
\hline $\begin{array}{l}\text { Microzone S4: } \\
S_{\mathrm{e}, \max }=2.2\left(\mathrm{~m} / \mathrm{s}^{2}\right) \\
T_{\mathrm{B}}=0.15(\mathrm{~s}) \\
T_{\mathrm{C}}=0.60(\mathrm{~s}) \\
T_{\mathrm{D}}=2.00(\mathrm{~s})\end{array}$ & $\begin{array}{l}\text { Microzone S3 mod: } \\
S_{\mathrm{e}, \max }=3.8\left(\mathrm{~m} / \mathrm{s}^{2}\right) \\
T_{\mathrm{B}}=0.10(\mathrm{~s}) \\
T_{\mathrm{C}}=0.55(\mathrm{~s}) \\
T_{\mathrm{D}}=1.87(\mathrm{~s})\end{array}$ \\
\hline
\end{tabular}

Figure 3: Eurocode 8: elastic response spectra for 5\% damping ratio related to the soil classes A to E microzonation of Yverdon: elastic response spectra for a return period of 475 years and 5\% damping ratio related to the four microzones S2, S3, S4, and S3 mod, respectively.
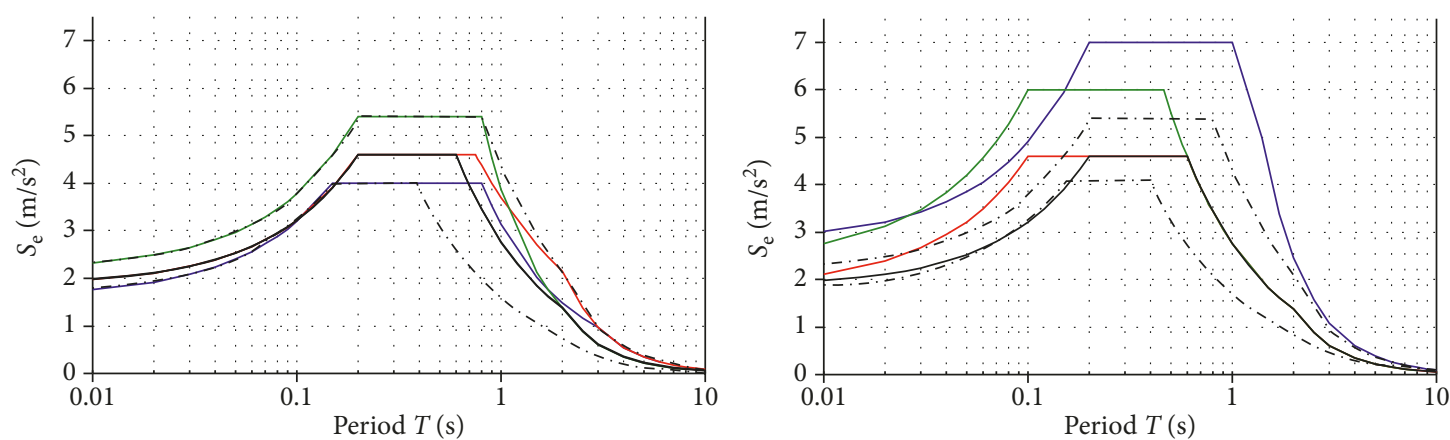

$\begin{array}{lc}\text { _ Microzone A1 } & -\cdot \text { Soil class A } \\ \text { Microzone A2 } & \text { Soil class C } \\ \text { — Microzone A3 } & \text { Microzone A2: } \\ \text { Microzone A1: } & S_{\mathrm{e}, \max }=4.6\left(\mathrm{~m} / \mathrm{s}^{2}\right) \\ S_{\mathrm{e}, \max }=4.0\left(\mathrm{~m} / \mathrm{s}^{2}\right) & T_{\mathrm{B}}=0.20(\mathrm{~s}) \\ T_{\mathrm{B}}=0.15(\mathrm{~s}) & T_{\mathrm{C}}=0.75(\mathrm{~s}) \\ T_{\mathrm{C}}=0.80(\mathrm{~s}) & T_{\mathrm{D}}=2.00(\mathrm{~s}) \\ T_{\mathrm{D}}=3.00(\mathrm{~s}) & \end{array}$

$\begin{array}{lc}\text { Microzone M1 } & -\cdots \text { Soil class A } \\ \text { Microzone M2 } & \text { Soil class C } \\ \text { Microzone M3 } & \text { - Soil class D } \\ \text { Microzone A3: } & \text { Microzone M3: } \\ S_{\mathrm{e}, \max }=5.4\left(\mathrm{~m} / \mathrm{s}^{2}\right) & S_{\mathrm{e}, \max }=6.0\left(\mathrm{~m} / \mathrm{s}^{2}\right) \\ T_{\mathrm{B}}=0.20(\mathrm{~s}) & T_{\mathrm{B}}=0.10(\mathrm{~s}) \\ T_{\mathrm{C}}=0.80(\mathrm{~s}) & T_{\mathrm{C}}=0.46(\mathrm{~s}) \\ T_{\mathrm{D}}=2.00(\mathrm{~s}) & T_{\mathrm{D}}=2.00(\mathrm{~s})\end{array}$

Figure 4: Microzonation of Sion and Martigny: elastic response spectra for a return period of 475 years and $5 \%$ damping ratio related the six microzones A1, A2, and A3, respectively, M1, M2, and M3 ([21]).

the response spectrum of microzone M2 is in accordance with the response spectrum of soil class $\mathrm{C}$. The upper corner period of response spectrum of microzone M3 is situated between the ones of EC8 soil class A and B.

\subsection{Selection and Modification of Ground-Motion Recordings.} Recordings are selected in order to match the considered response spectrum (target spectrum). Through a ranking process of the recordings of the database following the difference between their response spectrum and the target spectrum, recordings are ordered. The twelve highest ranked recordings form the recording set related to the considered target response spectrum. This selection is based on structural-engineering considerations only. As a consequence, earthquakes with different seismological features, such as magnitude or epicentral distance, are incorporated into the dataset. The main objective is to perform a statistical study of the nonlinear response of a structure undergoing any acceleration recording. Therefore, uncertainties related to recordings are not considered. 

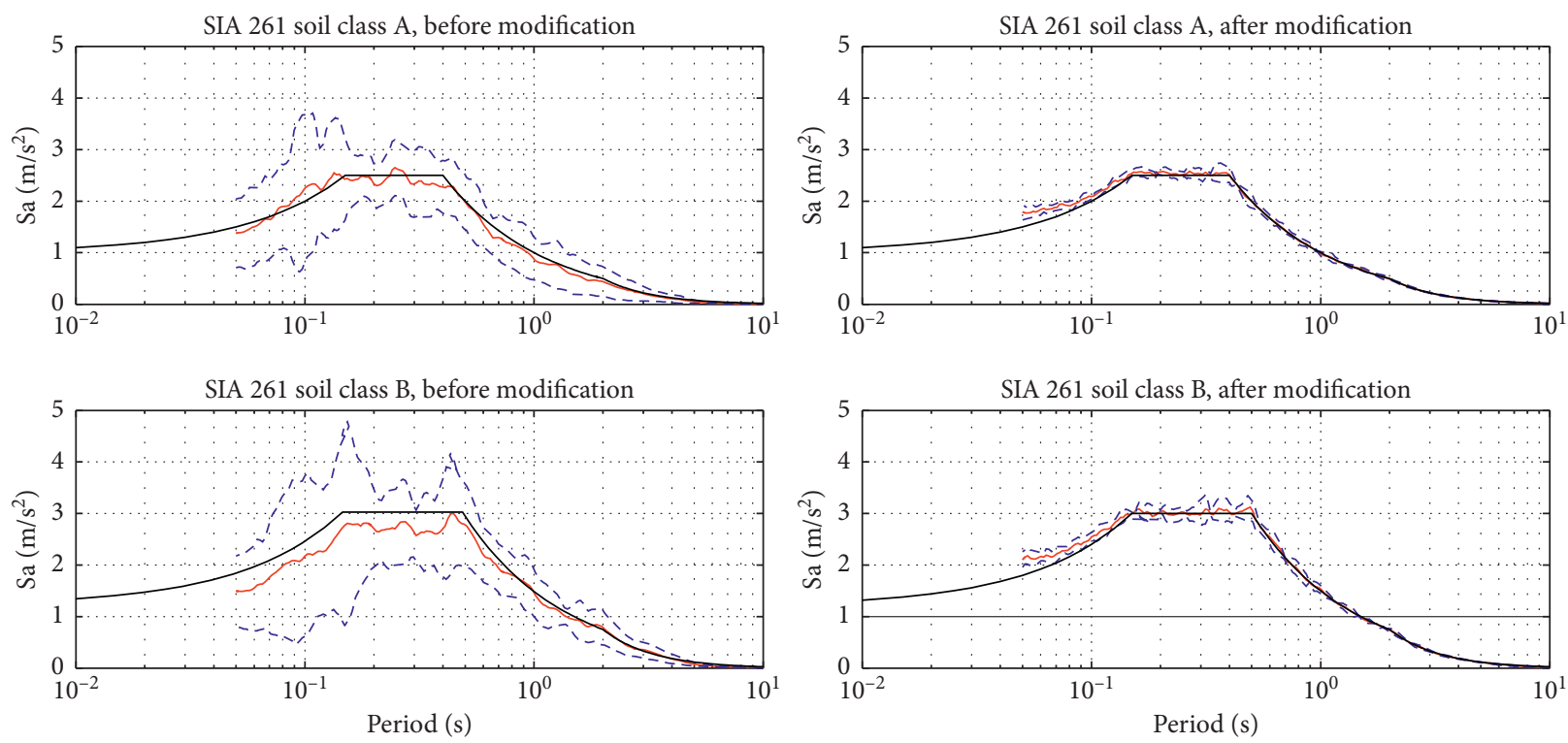

FiguRE 5: Statistical characteristics of the response spectra for the sets of the twelve recordings selected for the best fit to the response spectrum of the soil classes A and B of Eurocode 8 before (left) and after (right) modification for matching target spectrum.

The selected recordings are modified afterwards with the nonstationary spectral matching method of Abrahamson [22] in order to match the target spectrum individually. This technique has the decisive advantage to involve small modifications of the recordings, and thus, it is ensured that the related structural response in the nonlinear domain is not significantly affected. Therefore, this procedure allows the removal of the variability due to ground motion in order to evaluate exclusively the variability due to the estimation of the structural response. As shown by statistical characteristics of response spectra for the sets of twelve recordings before and after modification, the process repeated over ten iterations is very efficient for matching target spectra. As an example, response spectrum average and mean values plus and minus one standard deviation are plotted in Figure 5 for soil classes A and B of EC8. Figure 5 shows that the selection performed on the twelve recordings for each set leads already to a good match with respect to mean values. The plots after modification using the technique of Abrahamson show improvement in matching the target spectrum, as well as significant reduction in the variability.

3.3. Hysteretic Model. The nonlinear SDOF systems involved in this study are defined by their initial natural period, $T$ (corresponding to the initial stiffness of SDOF), the yield displacement, and the hysteretic model according to which the structure behaves in the nonlinear range. The modified Takeda model is used as a hysteretic model to compute the nonlinear responses because it provides an adequate simulation of the behavior of materials such as reinforced concrete. However, as already reported in other studies (e.g.,
$[23,24])$ the results obtained by using other models, such as the Q-model [25] or the Gamma model [26], would be similar and would not alter the conclusions presented within this work.

The Takeda model has been proposed in an original version by Takeda et al. [27]. The modified Takeda model has been developed independently by Otani [28] and Litton [29] and adapted by many researchers later on. The version of Allahabadi and Powell [30] is used hereafter. The forcedisplacement relationship, plotted in Figure 6, is specified through five parameters: the initial stiffness, the yield displacement, the postyield stiffness, a parameter governing the stiffness degradation $(\alpha)$, and a parameter $(\beta)$ specifying the target for the reloading curve. In order to simulate the behavior of conventional structures, appropriate values of the parameters $(\alpha=0.4$ and $\beta=0.0)$ are used in all analyses. A value of $5 \%$ has been selected for the hardening coefficient (postyield stiffness).

3.4. Computation. The methodology applied in this paper is schematically described in Figure 7. Simulations are performed for 18 values of the period, $T$, taken between 0.15 and $1 \mathrm{~s}$ and 12 instances of strength reduction factor, $R$, between 1.5 and 5. The typical value for the initial damping ratio $\xi$ is set to $5 \%$. Note that performing the computations with the strength reduction factor as a variable has the advantage that the level of the plateau is removed from the parameters. This approach provides a normalization of the results with respect to the plateau level. Furthermore, using a constant value for strength reduction factor $(R)$ instead of a constant ductility $(\mu)$ ensures the same level of nonlinearity for each ground motion. 


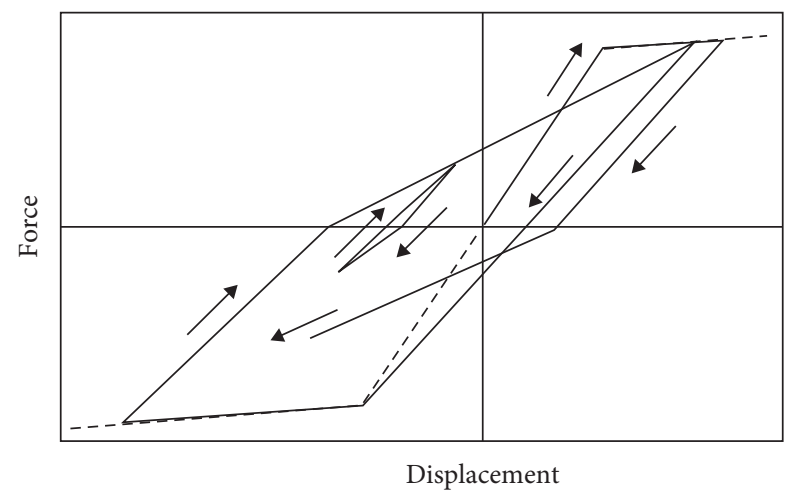

Figure 6: Force-displacement relationship defining the modified Takeda hysteretic model.

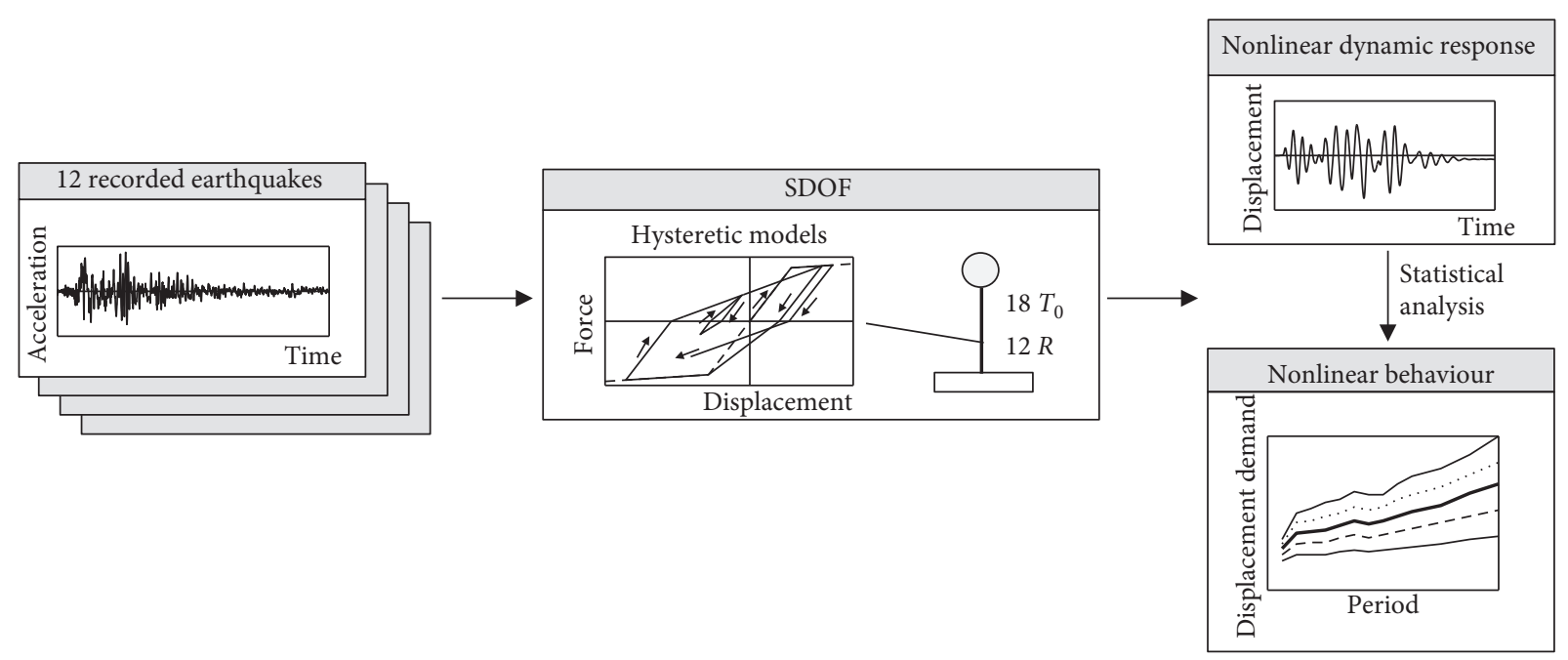

FIGURE 7: Schematic description of the methodology used for the investigations.

\section{Results}

The computed nonlinear displacement demands are assessed statistically by considering the average of the peak displacements (NLTHA displacement demand) obtained for the set of twelve ground motions corresponding to the considered response spectrum. The assessment is focused on the plateau of the considered response spectrum, i.e., only the values of the periods between the corner periods $T_{\mathrm{B}}$ and $T_{\mathrm{C}}$ are taken into account. The accuracy of the three methods (the N2 method, the optimized N2 method, and the Lin and Miranda method) is then first qualitatively calculated using the ratio of displacement demand prediction to NLTHA displacement demand for the 12 strength reduction factors. To account for the distribution of the nonlinear responses, threshold limits for a certain range around the value of 1 should be defined. As overestimation of the displacement demand is less problematic than underestimation, the threshold limits are not considered symmetrically. Consequently, underestimation by $10 \%$ and overestimation by $15 \%$ are defined as acceptable. Therefore, the method may be considered as accurate if the ratios remain within the thresholds of $90 \%$ and $115 \%$ along the plateau range.
Moreover, in order to avoid threshold effects, up to two values outside the defined limits are allowed. As an example, Figures 8-10 show the statistical results for the EC8 response spectrum for soil classes A, B, and D, respectively. The results for four selected values of the strength reduction factor are plotted. The results that are shown are typical of the performed study. For soil class A, the corner periods delimiting the plateau of the response spectrum are $T_{\mathrm{B}}=0.15 \mathrm{~s}$ and $T_{\mathrm{C}}=0.4 \mathrm{~s}$. The plots on Figure 8 for $R=2,3,4$, and 5 show that the N2 method is only accurate for a single value of the strength reduction factor, namely, $R=3$.

For soil class $\mathrm{B}$, the corner periods delimiting the response spectrum plateau are $T_{\mathrm{B}}=0.15 \mathrm{~s}$ and $T_{\mathrm{C}}=0.5 \mathrm{~s}$. The plots in Figure 9 for $R=1.5,2.5,3.5$, and 4.5 show that the N2 method is only accurate for the single value of the strength reduction factor of $R=3.5$. Displacement demand is systematically overestimated for small values of $R$ and underestimated for high values of $R$, especially for the very short period range (beginning of the plateau). By contrast, the optimized N2 method is accurate for all $R$ values. The Lin and Miranda method is accurate for small values of the strength reduction factor up to $R=2.5$ while displacement demand is systematically overestimated for higher values of $R$. 

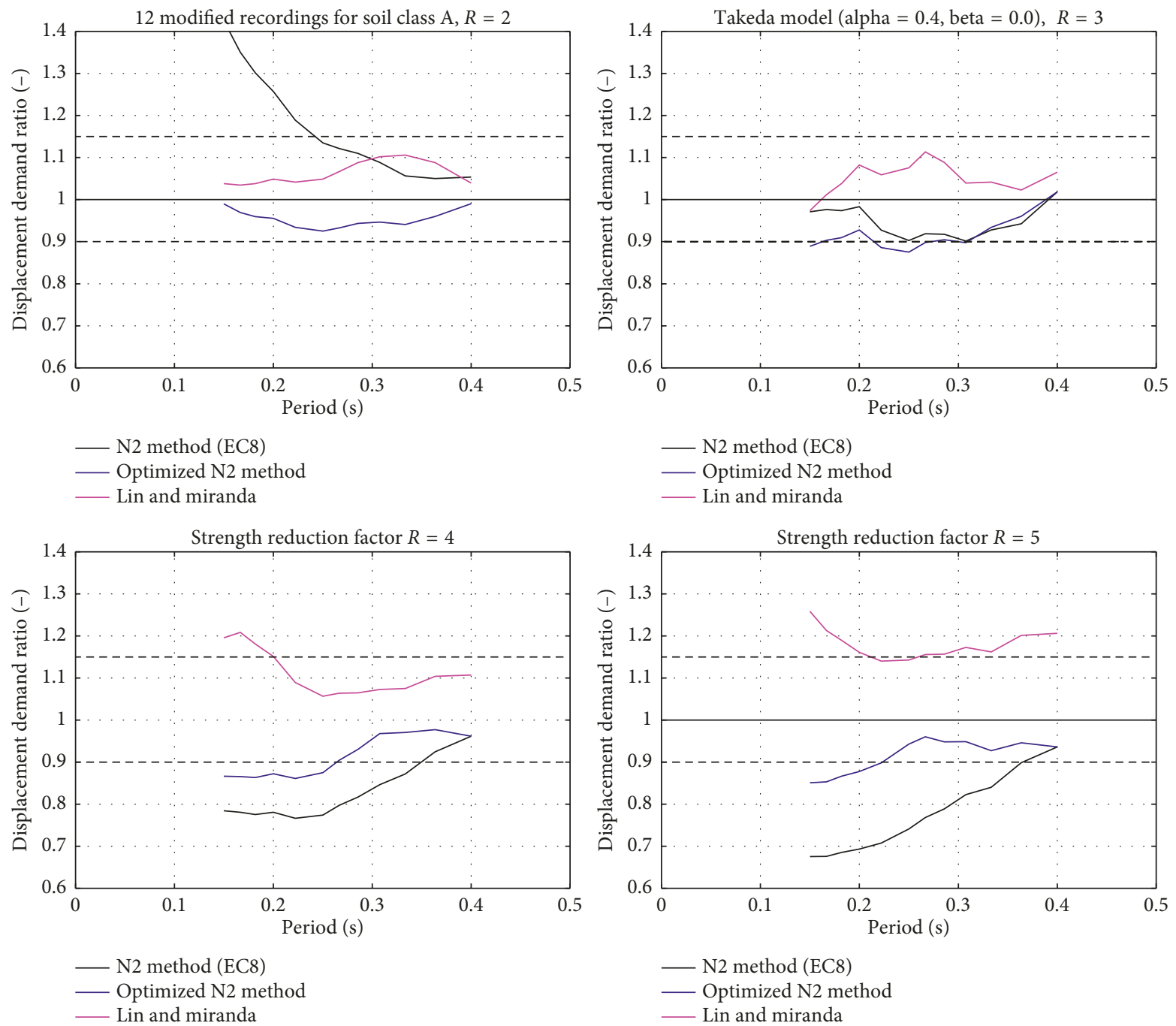

FIGURE 8: Assessment of the nonlinear displacement demands for soil class A and four values of strength reduction factors, $R=1$ to $R=5$. The ratio of predicted to actual (NLTHA) displacement demand is plotted with respect to the period. The plateau period range of the corresponding response spectrum $(0.15 \mathrm{~s}$ to $0.40 \mathrm{~s})$ is considered for the assessment.

For soil class D, the corner periods delimiting the response spectrum plateau are $T_{\mathrm{B}}=0.2 \mathrm{~s}$ and $T_{\mathrm{C}}=0.8 \mathrm{~s}$. The plots in Figure 10 for $R=2.25,2.75,3.25$, and 3.75 show that the N2 method may be considered as accurate for $R=3.25$ and relatively accurate for $R=3.75$. Again, the optimized N2 method is accurate for all $R$ values. By contrast, the Lin and Miranda method may be considered as accurate only for the value of $R=2.25$. For the other values of $R$, the inaccuracy of the Lin and Miranda method is essentially due to underestimations of displacement demands for the very beginning of the plateau, i.e., for periods close to $T_{\mathrm{B}}$, as shown by plots in Figure 10.

4.1. Results for Eurocode 8 and Microzonation Response Spectra. The assessment procedure described above is performed for response spectra-related soil classes of Eurocode 8, from A to D, and for few response spectra of detailed microzonation studies (M3, S3, and S3 modified).
The accuracy of the three simplified methods is then quantitatively assessed using the relative ratio of displacement demand prediction to NLTHA displacement demand $\left(|\Delta|_{T i}\right)$ for the different strength reduction factors. According to Diana et al. [11], the global average discrepancy value is used to assess the accuracy of the methods for the plateau period range for each analyzed strength reduction factor. The global average discrepancy is defined as follows:

$$
\overline{|\Delta|}_{R}=\frac{1}{t} \sum_{i=1}^{t}|\Delta|_{T_{i}}[\%]
$$

where $T=\left\{T_{1}, T_{2}, \ldots, T_{t}\right\}$, with $T_{1}=T_{\mathrm{B}}$ and $T_{t}=T_{\mathrm{C}}$.

The overall results for the $\mathrm{N} 2$ method are plotted in Figure 11 . The 3D surface corresponds to the global average discrepancy values $\left(\overline{|\Delta|}_{R}\right)$ in $z$-axis plotted with respect to the upper corner periods $\left(T_{C}\right)$ of the response spectrum plateau in $x$-axis and to the values of strength reduction factor $(R)$ in $y$-axis. 

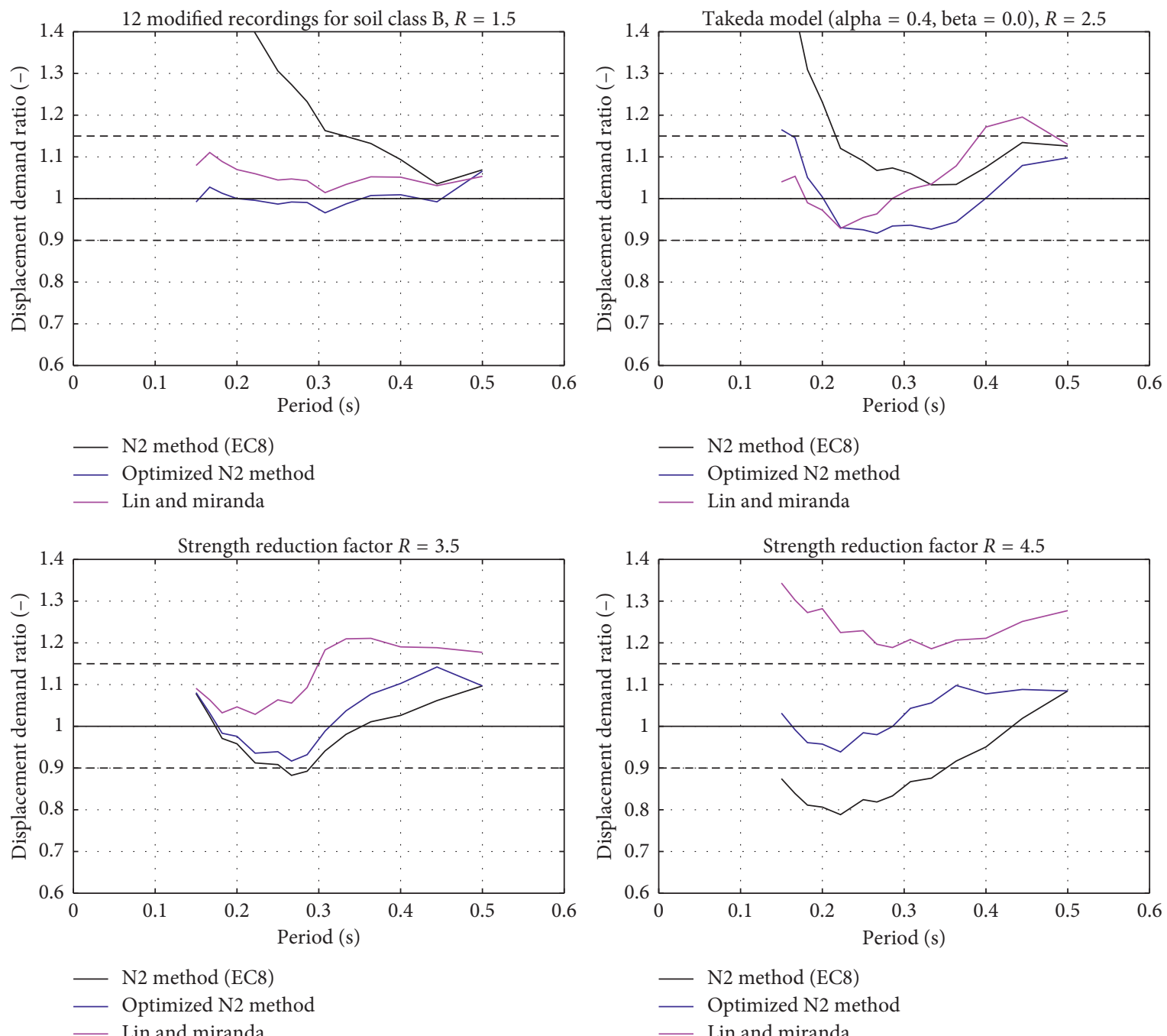

Figure 9: Assessment of the nonlinear displacement demands for soil class B and four values of strength reduction factors, $R=1.5$ to $R=4.5$. The ratio of predicted to actual (NLTHA) displacement demand is plotted with respect to the period. The plateau period range of the corresponding response spectrum $(0.15 \mathrm{~s}$ to $0.50 \mathrm{~s})$ is considered for the assessment.

The values of the global average discrepancy have a significant variation, ranging from about $4 \%$ at the minimum up to more than $40 \%$ at the maximum. Figure 11 shows that minimum global average discrepancies occur along a "valley" appearing at strength reduction factors $(R)$ values around 3.5. For low values of the upper corner periods $\left(T_{\mathrm{C}} \leq 0.5 \mathrm{~s}\right)$ of the response spectrum plateau, the position of the minimum is shifted down towards $R=3$.

The overall results for the optimized N2 method and the Lin and Miranda method are plotted side by side in Figure 12. The accuracy of the optimized N2 method is evidenced by Figure 12 (left) since the 3D surface of the global average discrepancy values is relatively flat and does not reach $10 \%$ at any point, ranging from $2 \%$ to $9 \%$. The accuracy of the Lin and Miranda method is inferior to the one of the optimized N2 method. In Figure 12 (right) the 3D plots of the global average discrepancy of the Lin and Miranda method are flat, in a similar way to the optimized N2 method, at low values of strength reduction factors of up to about $R=2.5$. Thus, both methods are accurate for this range of $R$. However, the discrepancies of the Lin and Miranda method significantly increase for higher values of $R$, especially for low values of the upper corner periods $\left(T_{\mathrm{C}}\right)$.

Based on the results described above, a value of $8.5 \%$ is selected in the following as a threshold for the global average discrepancy to evaluate the accuracy of the methods. Such a value ensures that the displacement demand predictions practically remain within an acceptable range of $90 \%$ and $115 \%$ of the NLTHA displacement demand along the plateau range.

In addition, the overall accuracy results are plotted in Figure 13 using a pixelized representation. Figure 13 contains a separate plot for each investigated method. In each plot, pixel coordinates correspond to the values of strength reduction factor $(R)$ in $y$-axis with respect to the upper corner periods $\left(T_{\mathrm{C}}\right)$ of the response spectrum plateau in $x$ axis. As a consequence, the results for EC8 soil class B for instance appear along the vertical lines at $T_{C}=0.5 \mathrm{~s}$. The 

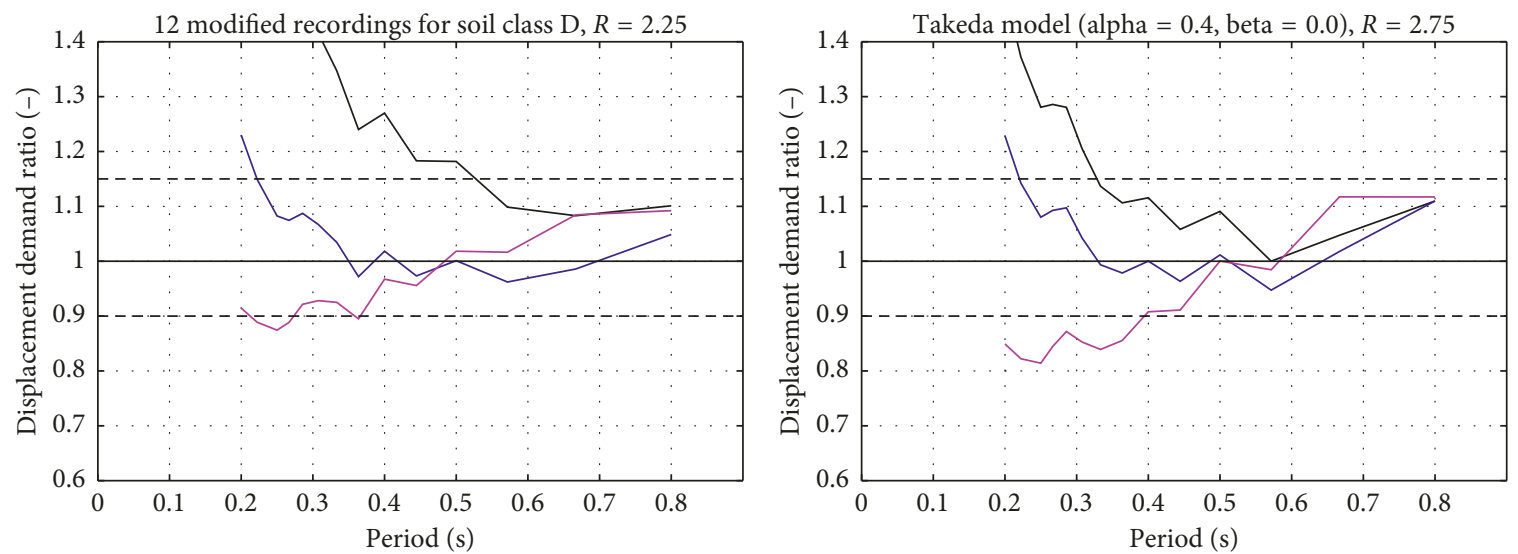

- N2 method (EC8)

— Optimized N2 method

_ Lin and miranda
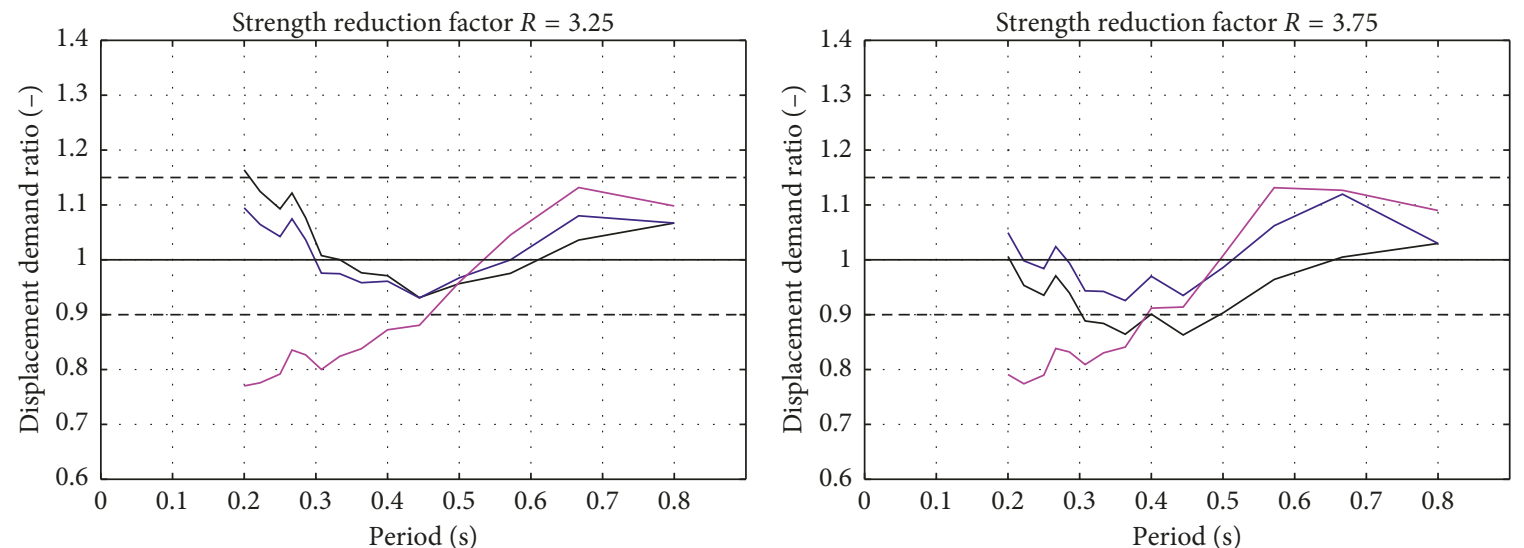

N2 method (EC8)
_ Optimized N2 method
_ Lin and miranda

— N2 method (EC8)

_ Optimized N2 method

_ Lin and miranda

Figure 10: Assessment of the nonlinear displacement demands for soil class $\mathrm{D}$ and four values of strength reduction factors, $R=2.25$ to $R=3.75$. The ratio of predicted to actual (NLTHA) displacement demand is plotted with respect to the period. The plateau period range of the corresponding response spectrum $(0.20 \mathrm{~s}$ to $0.80 \mathrm{~s})$ is considered for the assessment.

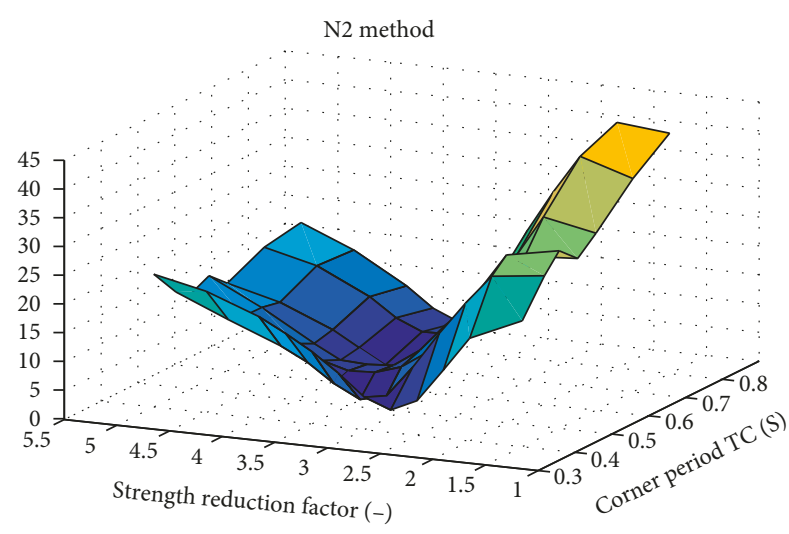

Figure 11: Overall results for the N2 method. The global average discrepancy values are plotted in $3 \mathrm{D}$ ( $z$-axis) with respect to the strength reduction factor values $(R)$ in $y$-axis and upper corner period of the plateau $\left(T_{\mathrm{C}}\right)$ in $x$-axis. A minimum "valley" appears for $R$ values around $R=3.5$. pixels are full if the method is accurate for the corresponding couple of values $\left(R\right.$ and $\left.T_{C}\right)$ and empty if the method is not considered as accurate. Additional computations are performed for intermediate values of upper corner period $T_{C}$ according to specific response spectra of microzonation studies of the cities of Martigny and Yverdon (see Section 3.1). The response spectrum of microzone M3 for Martigny has an upper corner period for the plateau of $T_{C}=0.46 \mathrm{~s}$ (Figure 4). The set of 12 recordings selected for microzone S3 of the spectral microzonation study of the city of Yverdon [20] was used one more time but modified to match an EC8 compatible response spectrum with an upper corner period for the plateau of $T_{C}=0.7 \mathrm{~s}$. Another set of 12 recordings selected for the upgrade of microzone S3 of Yverdon was used to develop the EC8 compatible response spectrum with upper corner plateau period of $T_{\mathrm{C}}=0.55 \mathrm{~s}$. Consequently, the seven upper corner periods $\left(T_{C}\right)$ of response spectra considered are $0.4 \mathrm{~s}$ for EC8 soil class A; $0.46 \mathrm{~s}$ for microzone 

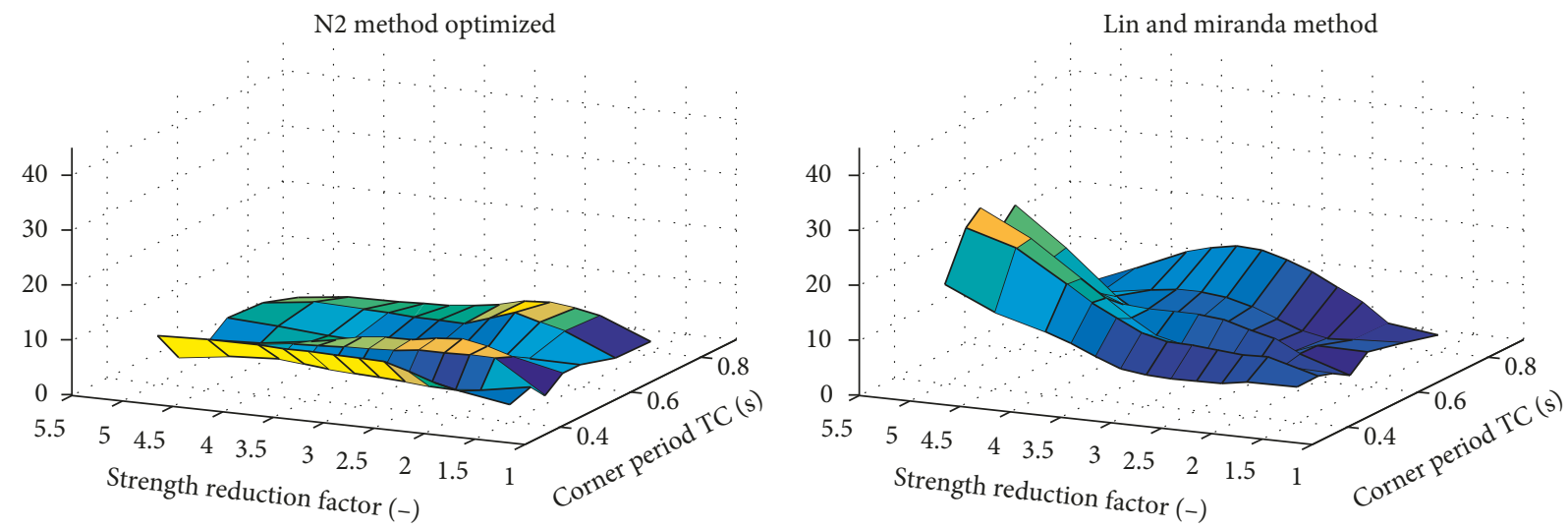

FIGURE 12: Overall results for the optimized N2 method (left) and Lin and Miranda method (right). The 3D surface plot of the global average discrepancy values is flat and low for the optimized N2 method, meaning that the method is all over accurate. The Lin and Miranda method shows similar trend but for low values of strength reduction factors only.
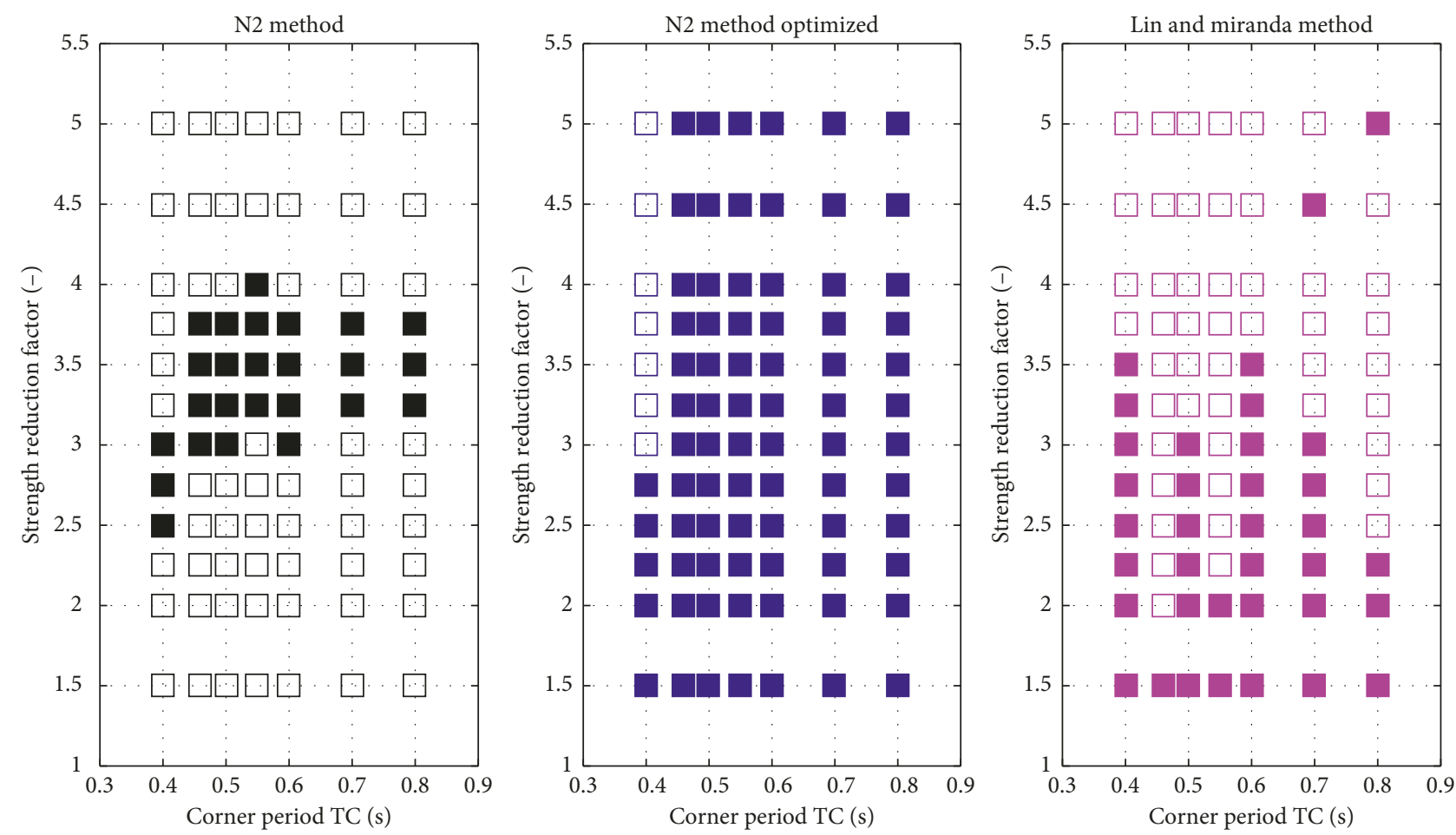

Figure 13: Overall results for the accuracy assessment of the 3 investigated methods. Pixel coordinates correspond to strength reduction factor values $(R)$ and upper corner period of the plateau $\left(T_{\mathrm{C}}\right)$. Pixels are full if the method is accurate for the corresponding couple of values $\left(R, T_{\mathrm{C}}\right)$.

M3 (Martigny); $0.5 \mathrm{~s}$ for EC8 soil class B; $0.55 \mathrm{~s}$ for modified microzone S3; $0.6 \mathrm{~s}$ for EC8 soil class $\mathrm{C}$; $0.7 \mathrm{~s}$ for microzone $\mathrm{S} 3$; and $0.8 \mathrm{~s}$ for soil class $\mathrm{D}$. The 12 strength reduction factors considered are: $1.50 ; 2.00 ; 2.25 ; 2.50 ; 2.75 ; 3.00 ; 3.25$; $3.50 ; 3.75 ; 4.00 ; 4.50$; and 5.00 .

Figure 13 shows that the accuracy range of the N2 method is essentially restricted to values of strength reduction factors between $R=3$ and $R=3.75$. This range even decreases with increasing values of the upper corner period of the plateau $\left(T_{\mathrm{C}}\right)$. For EC8 soil class $\mathrm{D}$ with $T_{\mathrm{C}}=0.8 \mathrm{~s}$, the $\mathrm{N} 2$ method is only accurate for strength reduction factors between $R=3.25$ and $R=3.75$. The accuracy range is shifted down for short values of $T_{\mathrm{C}}$. For EC8 soil class A with $T_{C}=0.4 \mathrm{~s}$, the $\mathrm{N} 2$ method is accurate for strength reduction factors between $R=2.5$ and $R=3$. For smaller values of $R$, the N2 method overestimates the displacement demand and for higher values of $R$, displacement demand is underestimated. By contrast, the optimized N2 method is generally 
accurate. Except for values of strength reduction factor $R=3$ and above in case of EC8 soil class A response spectrum, the optimized N2 method is accurate for all soil classes and microzones considered and for all $R$ values. The domain over which the Lin and Miranda method is accurate may not be obviously described. The Lin and Miranda method tends to be accurate for small values of strength reduction factors $(R \leq 3.0)$. For EC8 soil class A response spectrum, the Lin and Miranda method performs well up to a value of $R=3.5$.

4.2. Results for Response Spectra with Different Shapes after the Plateau. For EC8 response spectra, the shape after the plateau is defined by a constant pseudovelocity range $(1 / T$ from corner period $T_{\mathrm{C}}$ to period $T_{\mathrm{D}}$ ) followed by a constant relative displacement range $\left(1 / T^{2}\right.$ after $\left.T_{\mathrm{D}}\right)$. However, different shapes after the plateau, more specifically gentler or steeper decreasing branches, may be specified for instance in case of detailed spectral microzonation studies. The impact of steeper or gentler branches than constant pseudovelocity $(1 / T)$ decreasing branches on the accuracy of the displacement demand prediction is also preliminarily investigated in this study. The influence of the shape of the decreasing branch of the response spectrum is found to be particularly significant. Figure 14 shows the results obtained for EC8 soil class C and similar response spectra. In these plots, pixel coordinates correspond to the values of strength reduction factor $(R)$ in $y$-axis with respect to the exponent of the declining branch $\left(1 / T^{\alpha}\right)$ of the response spectrum plateau in $x$-axis. As a consequence, the results for EC8 soil class $\mathrm{C}$ appear along the vertical lines at $\alpha=1.0$ in Figure 14. As in previous figures, the pixels are full if the method is accurate for the corresponding couple of values $(R, \alpha)$ and empty if the method is considered inaccurate.

Additional computations are performed for specific response spectra, of the Yverdon spectral microzonation study, that have the same upper corner period $T_{C}$ as soil class $\mathrm{C}\left(T_{\mathrm{C}}=0.6 \mathrm{~s}\right)$ but other values of the exponent of the decreasing branch $\left(1 / T^{\alpha}\right)$ after the plateau. The response spectrum of microzone S4 for Yverdon has an exponent of the decreasing branch after the plateau of $\alpha=0.74$ [20]. The response spectrum of microzone S2 for Yverdon has an exponent of the decreasing branch after the plateau of $\alpha=$ 1.6 [20]. The set of 12 recordings selected for microzone S3 for Yverdon, that has been used for simulations shown in Figures 11-13 [20], are modified to match a corresponding response spectrum with an exponent of the decreasing branch after the plateau of $\alpha=0.87$. The set of 12 recordings selected for microzone S4 of Yverdon are modified to match a corresponding response spectrum with an exponent of the decreasing branch after the plateau of $\alpha=0.66$.

Figure 14 shows that the accuracy domain for the N2 method is strongly affected by the value of the exponent of the decreasing branch after the plateau. The accuracy domain is significantly reduced for $\alpha=0.66$ and shifted up towards higher values of strength reduction factor for $\alpha=1.6$. The accuracy domains for the optimized N2 method and the Lin and Miranda method are less affected for values of $\alpha$ smaller than one but they are shifted down for $\alpha=1.6$. For the Lin and Miranda method, the domain of accuracy even increases for values of $\alpha$ smaller than one.

Figure 15 shows the results obtained for EC8 soil class D and similar response spectra. The results for EC8 soil class D appear along the vertical lines at $\alpha=1.0$. Additional computations are performed for specific response spectra of the spectral microzonation study of the city of Sion with same (or nearly the same for microzone A2) upper corner period $T_{\mathrm{C}}$ as soil class $\mathrm{D}\left(T_{\mathrm{C}}=0.8 \mathrm{~s}\right)$ but with different values of the exponent of the decreasing branch $\left(1 / T^{\alpha}\right)$ after the plateau. The response spectrum of microzone A2 for Sion has an exponent of the declining branch after the plateau of $\alpha=$ 0.77 (Figure 4). The response spectrum of microzone A1 for Sion has an exponent of the declining branch after the plateau of $\alpha=1.08$ (Figure 4). The response spectrum of microzone A3 for Sion has an exponent of the declining branch after the plateau of $\alpha=1.49$ (Figure 4). Figure 15 shows a similar yet more pronounced trend than Figure 14 regarding the accuracy domains for the three investigated methods. The N2 method may even be considered as completely inaccurate in case of $\alpha=0.77$. The accuracy domain for the optimized N2 method is also strongly reduced for $\alpha=0.77$. The accuracy domain is again shifted towards higher values of strength reduction factor for $\alpha=$ 1.49 for the N2 method. By contrast, the accuracy domain of the three methods is not affected for $\alpha=1.08$. The accuracy domains for the Lin and Miranda method are not significantly affected by the values of $\alpha$.

\section{Summary and Conclusions}

The accuracy of three methods for nonlinear seismic displacement demand predictions is carefully evaluated in this study: the simplified version of the N2 method, the optimized N2 method, and the Lin and Miranda method. The investigation is performed for the plateau range of response spectra corresponding to the Eurocode 8 Type- 1 soil classes and to response spectra of detailed microzonation studies. Accuracy is assessed through a comparison of the displacement demand computed using nonlinear time-history analysis (NLTHA) with the displacement demand predicted by the three methods.

The accuracy domain significantly depends on the response spectrum plateau extension (value of the upper corner period, $T_{\mathrm{C}}$ ). Furthermore, the accuracy of displacement demand predictions is found to be dependent on the shape of the response spectrum after the plateau. A less steeply decreasing branch after the plateau affects the accuracy. The study focuses on SDOF and on hysteretic models featuring ductile structural behavior under seismic actions. These choices reflect the objectives of the study. Even if some slight differences arise when using MDOF representations (e.g., [31]), the essential characteristics of the seismic response are captured by SDOF models.

The results show that the simplified version of the N2 method provides accurate predictions for strength reduction factor values between $R=3$ and $R=3.75$. This range decreases further with increasing values of the upper 

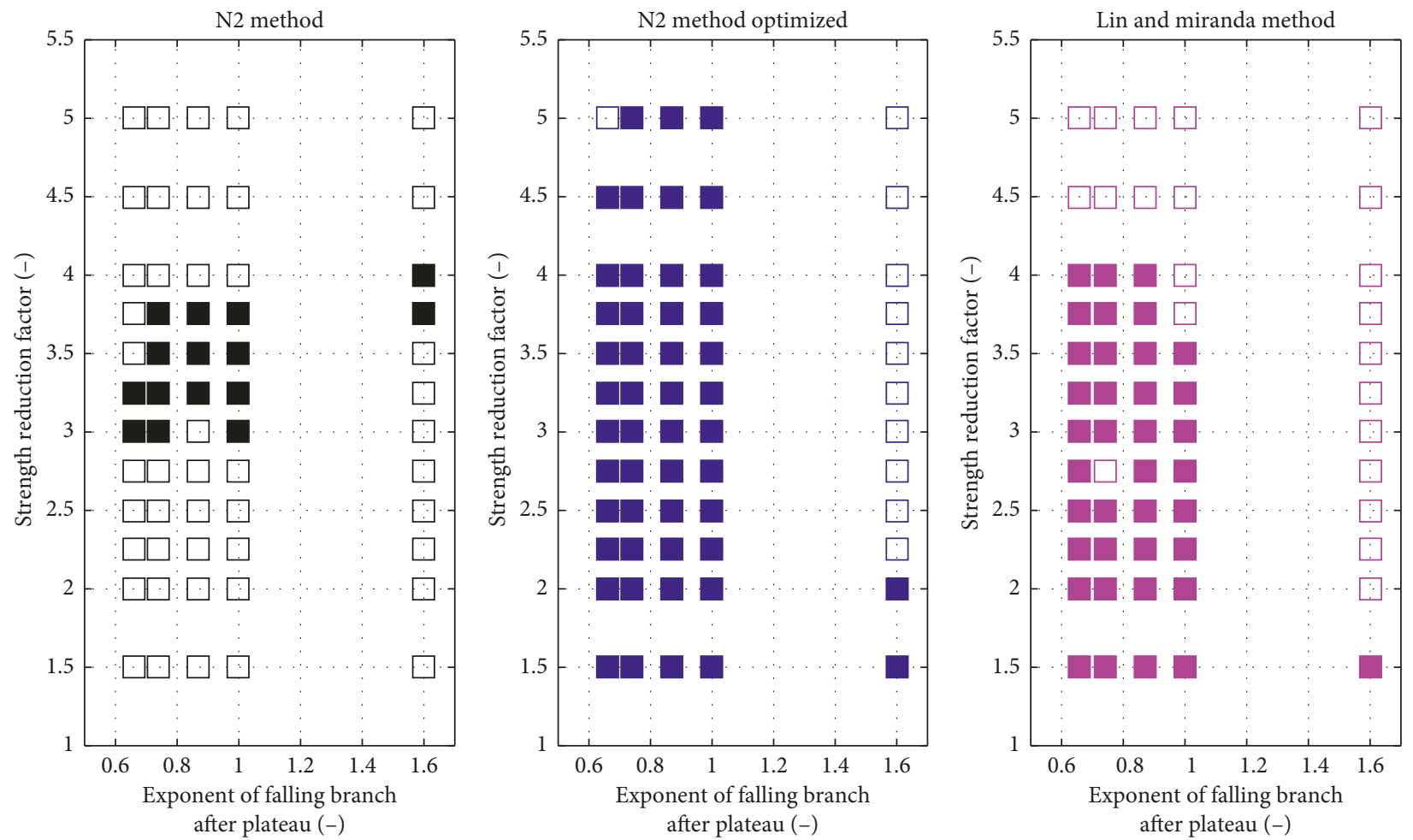

FIGURE 14: Accuracy assessment of the 3 investigated methods for soil class $C$ with respect to the exponent of the decreasing branch after the plateau of the response spectrum. Pixel coordinates correspond to strength reduction factor values $(R)$ and exponent of the decreasing branch $(\alpha)$. Pixels are full if the method is accurate for the corresponding couple of values $(R, \alpha)$.
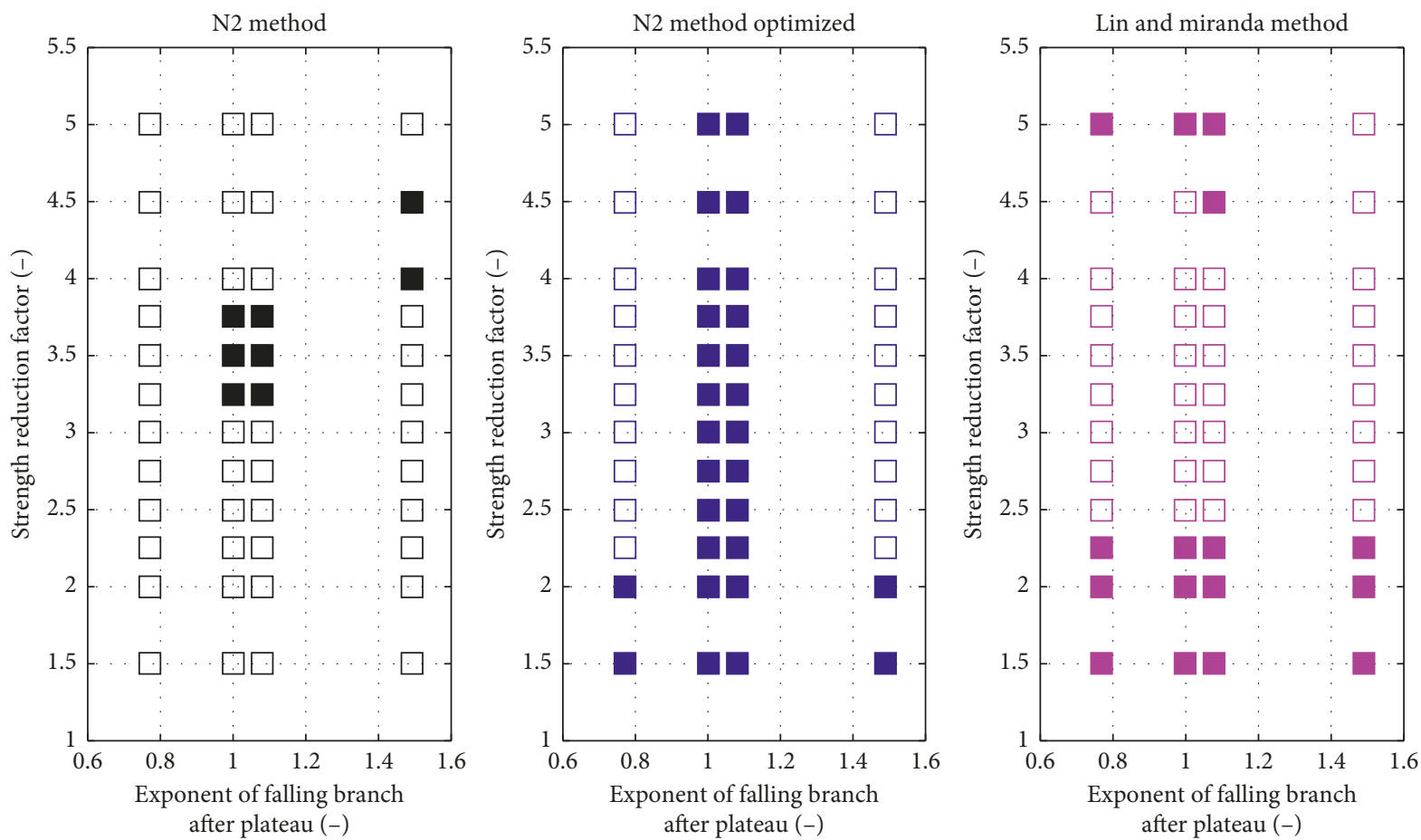

FIGURE 15: Accuracy assessment of the three investigated methods for soil class D with respect to the exponent of the decreasing branch after the plateau of the response spectrum. 


\begin{tabular}{|c|c|c|c|c|c|c|c|c|c|c|c|c|c|c|c|c|c|}
\hline \multirow{2}{*}{ Earthquake } & \multirow{2}{*}{ Date } & \multirow{2}{*}{ Magnitude } & \multirow{2}{*}{$\begin{array}{c}\text { Distance } \\
(\mathrm{km})\end{array}$} & \multirow{2}{*}{$\begin{array}{c}\text { PGA } \\
\left(\mathrm{m} / \mathrm{s}_{2}\right)\end{array}$} & \multirow{2}{*}{ Soil A } & \multirow{2}{*}{ Soil B } & \multirow{2}{*}{ Soil C } & \multirow{2}{*}{ Soil D } & \multicolumn{3}{|c|}{ Sion } & \multicolumn{2}{|c|}{ Martigny } & & & lon & \\
\hline & & & & & & & & & $\mathrm{A} 1$ & $\mathrm{~A} 2$ & $\mathrm{~A} 3$ & M2 & M3 & $\mathrm{S} 2$ & S3 & $\mathrm{S} 4$ & S3mod \\
\hline Friuli (as) & 11.09 .1976 & $5.3 \mathrm{Mw}$ & 8 & 1.931 & $\mathrm{X}$ & & & & & & & & & & & & \\
\hline Friuli (as) & 11.09 .1976 & $5.5 \mathrm{Mw}$ & 10 & 2.260 & & & & & & & & $\mathrm{X}$ & & & & & \\
\hline Friuli (as) & 16.09 .1977 & $5.4 \mathrm{Mw}$ & 14 & 0.910 & $\mathrm{X}$ & & & & & & & & & & & & \\
\hline Volvi & 04.07 .1978 & $5.12 \mathrm{Ms}$ & 16 & 1.125 & $\mathrm{X}$ & & & & & & & & & & & & \\
\hline El Asnam (as) & 08.11 .1980 & $5.2 \mathrm{Mw}$ & 18 & 0.946 & $\mathrm{X}$ & & & & & & & & & & & & \\
\hline Friuli (as) & 15.09 .1976 & $6 \mathrm{Mw}$ & 11 & 1.069 & & $\mathrm{X}$ & $\mathrm{X}$ & & & & & & & & $\mathrm{X}$ & $\mathrm{X}$ & \\
\hline Friuli (as) & 15.09 .1976 & $6 \mathrm{Mw}$ & 17 & 2.319 & & & & & & & & & & $\mathrm{X}$ & & & $\mathrm{X}$ \\
\hline Basso Tirreno & 15.04 .1978 & $6 \mathrm{Mw}$ & 18 & 1.585 & & & $\mathrm{X}$ & $\mathrm{X}$ & & & & & & $\mathrm{X}$ & $\mathrm{X}$ & & $\mathrm{X}$ \\
\hline Valnerina & 19.09 .1979 & $5.8 \mathrm{Mw}$ & 5 & 2.012 & & & & & & & & & & $\mathrm{X}$ & & & \\
\hline Friuli & 06.05 .1976 & $6.5 \mathrm{Mw}$ & 27 & 3.499 & & & & & & & $\mathrm{X}$ & & & & & & \\
\hline Volvi & 20.06 .1978 & $6.2 \mathrm{Mw}$ & 29 & 1.430 & & $\mathrm{X}$ & $\mathrm{X}$ & & & & & & & $\mathrm{X}$ & $\mathrm{X}$ & & $\mathrm{X}$ \\
\hline Montenegro & 24.05 .1979 & $6.2 \mathrm{Mw}$ & 33 & 2.652 & & & & & & & & $\mathrm{X}$ & & $\mathrm{X}$ & & & \\
\hline Montenegro & 24.05 .1979 & $6.2 \mathrm{Mw}$ & 8 & 2.624 & & & & & & & $\mathrm{X}$ & & & & & & \\
\hline Montenegro & 24.05 .1979 & $6.2 \mathrm{Mw}$ & 30 & 0.754 & $\mathrm{X}$ & & & & & & & & & & & & \\
\hline Montenegro & 24.05 .1979 & $6.2 \mathrm{Mw}$ & 17 & 2.703 & & $\mathrm{X}$ & & & & & & & & & & & \\
\hline Alkion & 25.02 .1981 & $6.3 \mathrm{Mw}$ & 25 & 1.176 & & $\mathrm{X}$ & $\mathrm{X}$ & $\mathrm{X}$ & & & & & & $\mathrm{X}$ & $\mathrm{X}$ & & $\mathrm{X}$ \\
\hline Aigion & 15.06 .1995 & $6.5 \mathrm{Mw}$ & 43 & 0.911 & & & $\mathrm{X}$ & & & & & & & & & $\mathrm{X}$ & \\
\hline Adana & 27.06.1998 & $6.3 \mathrm{Mw}$ & 30 & 2.644 & & & & & & $\mathrm{X}$ & $\mathrm{X}$ & & $\mathrm{X}$ & & & & \\
\hline Montenegro & 15.04 .1979 & $6.9 \mathrm{Mw}$ & 65 & 2.509 & & & $\mathrm{X}$ & $\mathrm{X}$ & & & & & & & $\mathrm{X}$ & & $\mathrm{X}$ \\
\hline Montenegro & 15.04 .1979 & $6.9 \mathrm{Mw}$ & 21 & 2.198 & & & & & $\mathrm{X}$ & $\mathrm{X}$ & $\mathrm{X}$ & $\mathrm{X}$ & $\mathrm{X}$ & $\mathrm{X}$ & & & $\mathrm{X}$ \\
\hline Campano & 23.11 .1980 & $6.9 \mathrm{Mw}$ & 23 & 1.776 & & & & $\mathrm{X}$ & $\mathrm{X}$ & $\mathrm{X}$ & & & & & & & $\mathrm{X}$ \\
\hline Campano & 23.11 .1980 & $6.9 \mathrm{Mw}$ & 26 & 0.903 & & & $\mathrm{X}$ & & & & & & & & & $\mathrm{X}$ & \\
\hline Campano & 23.11 .1980 & $6.9 \mathrm{Mw}$ & 16 & 1.725 & & & & $\mathrm{X}$ & $\mathrm{X}$ & $\mathrm{X}$ & & $\mathrm{X}$ & & & $\mathrm{X}$ & & \\
\hline Campano & 23.11 .1980 & $6.9 \mathrm{Mw}$ & 48 & 1.362 & & & & & & & & & & & & & $\mathrm{X}$ \\
\hline Campano & 23.11 .1980 & $6.9 \mathrm{Mw}$ & 33 & 0.975 & $\mathrm{X}$ & $\mathrm{X}$ & & & & & & & & & & $\mathrm{X}$ & \\
\hline Campano & 23.11 .1980 & $6.9 \mathrm{Mw}$ & 32 & 3.166 & & & & & & & & $\mathrm{X}$ & $\mathrm{X}$ & & & & \\
\hline Alkion & 24.02 .1981 & $6.6 \mathrm{Mw}$ & 33 & 3.036 & & & & & $\mathrm{X}$ & $\mathrm{X}$ & $\mathrm{X}$ & $\mathrm{X}$ & $\mathrm{X}$ & & & & \\
\hline Alkion & 24.02 .1981 & $6.6 \mathrm{Mw}$ & 33 & 2.256 & & & & & & & & & $\mathrm{X}$ & & & & \\
\hline Alkion & 24.02 .1981 & $6.6 \mathrm{Mw}$ & 34 & 2.838 & & & & & $\mathrm{X}$ & $\mathrm{X}$ & $\mathrm{X}$ & $\mathrm{X}$ & & $\mathrm{X}$ & & & \\
\hline Spitak & 07.12 .1988 & $6.7 \mathrm{Mw}$ & 36 & 1.796 & & & & $\mathrm{X}$ & $\mathrm{X}$ & & & & & & $\mathrm{X}$ & & $\mathrm{X}$ \\
\hline Strofades & 18.11.1997 & $6.6 \mathrm{Mw}$ & 144 & 0.907 & $\mathrm{X}$ & & & & & & & & & & & $\mathrm{X}$ & \\
\hline Strofades & 18.11 .1997 & $6.6 \mathrm{Mw}$ & 32 & 1.289 & & $\mathrm{X}$ & & & & & & & & & & & $\mathrm{X}$ \\
\hline Tabas & 16.09 .1978 & $7.4 \mathrm{Mw}$ & 55 & 1.003 & $\mathrm{X}$ & $\mathrm{X}$ & & & & & & & & & & $\mathrm{X}$ & \\
\hline Tabas & 16.09 .1978 & $7.4 \mathrm{Mw}$ & 11 & 3.779 & & & & & & & & & $\mathrm{X}$ & & & & \\
\hline Tabas & 16.09 .1978 & $7.4 \mathrm{Mw}$ & 100 & 1.002 & $\mathrm{X}$ & & & & & & & & & & & & \\
\hline Manjil & 20.06 .1990 & $7.4 \mathrm{Mw}$ & 81 & 0.951 & $\mathrm{X}$ & $\mathrm{X}$ & & & & & & & & & & $\mathrm{X}$ & \\
\hline Manjil & 20.06 .1990 & $7.4 \mathrm{Mw}$ & 131 & 1.341 & & & & $\mathrm{X}$ & $\mathrm{X}$ & $\mathrm{X}$ & & & & & $\mathrm{X}$ & & \\
\hline Gulf of Akaba & 22.11 .1995 & $7.1 \mathrm{Mw}$ & 93 & 0.894 & $\mathrm{X}$ & $\mathrm{X}$ & & & & & & & & & & $\mathrm{X}$ & \\
\hline Izmit & 17.08.1999 & $7.6 \mathrm{Mw}$ & 113 & 2.580 & & & & & & $\mathrm{X}$ & $\mathrm{X}$ & $\mathrm{X}$ & $\mathrm{X}$ & & & & \\
\hline Izmit & 17.08.1999 & $7.6 \mathrm{Mw}$ & 172 & 0.974 & $\mathrm{X}$ & & & & & & & & & & & $\mathrm{X}$ & \\
\hline Izmit & 17.08.1999 & $7.6 \mathrm{Mw}$ & 110 & 1.698 & & & $\mathrm{X}$ & & & & & & & & & & \\
\hline Izmit & 17.08.1999 & $7.6 \mathrm{Mw}$ & 48 & 2.334 & & & $\mathrm{X}$ & $\mathrm{X}$ & $\mathrm{X}$ & & & $\mathrm{X}$ & & $\mathrm{X}$ & $\mathrm{X}$ & & $\mathrm{X}$ \\
\hline Izmit & 17.08.1999 & $7.6 \mathrm{Mw}$ & 48 & 1.329 & & & & & & & & & & $\mathrm{X}$ & & & \\
\hline Izmit & 17.08.1999 & $7.6 \mathrm{Mw}$ & 78 & 1.040 & & $\mathrm{X}$ & $\mathrm{X}$ & $\mathrm{X}$ & & & & & & & $\mathrm{X}$ & $\mathrm{X}$ & \\
\hline Izmit & 17.08.1999 & $7.6 \mathrm{Mw}$ & 101 & 1.611 & & & & & & & & & & & & & $\mathrm{X}$ \\
\hline Izmit & 17.08.1999 & $7.6 \mathrm{Mw}$ & 96 & 1.120 & & $\mathrm{X}$ & $\mathrm{X}$ & & & & & & & $\mathrm{X}$ & $\mathrm{X}$ & $\mathrm{X}$ & \\
\hline Izmit & 17.08.1999 & $7.6 \mathrm{Mw}$ & 10 & 2.192 & & & & $\mathrm{X}$ & $\mathrm{X}$ & $\mathrm{X}$ & & & & & & & \\
\hline Izmit & 17.08.1999 & $7.6 \mathrm{Mw}$ & 39 & 1.266 & & & & $\mathrm{X}$ & $\mathrm{X}$ & $\mathrm{X}$ & & & & & $\mathrm{X}$ & & \\
\hline Izmit & 17.08.1999 & $7.6 \mathrm{Mw}$ & 34 & 3.542 & & & & $\mathrm{X}$ & $\mathrm{X}$ & & $\mathrm{X}$ & $\mathrm{X}$ & $\mathrm{X}$ & & & & \\
\hline Izmit & 17.08.1999 & $7.6 \mathrm{Mw}$ & 20 & 2.903 & & & & & & $\mathrm{X}$ & $\mathrm{X}$ & & & & & & \\
\hline Izmit & 17.08 .1999 & $7.6 \mathrm{Mw}$ & 20 & 2.903 & & & & & & & $\mathrm{X}$ & & & & & & \\
\hline Izmit & 17.08 .1999 & $7.6 \mathrm{Mw}$ & 103 & 0.871 & & $\mathrm{X}$ & $\mathrm{X}$ & & & & & & & & & $\mathrm{X}$ & \\
\hline Ano Liosia & 07.09.1999 & $6.0 \mathrm{Mw}$ & 16 & 2.601 & & & & & & & & & & $\mathrm{X}$ & & & \\
\hline Duzce 1 & 12.11.1999 & $7.2 \mathrm{Mw}$ & 22 & 2.902 & & & & & & & & & $\mathrm{X}$ & & & & \\
\hline Kalamata & 13.09 .1986 & $5.9 \mathrm{Mw}$ & 10 & 2.909 & & & & & $\mathrm{X}$ & $\mathrm{X}$ & $\mathrm{X}$ & $\mathrm{X}$ & $\mathrm{X}$ & & & & \\
\hline Umbria Marche & 26.09 .1997 & $5.7 \mathrm{Mw}$ & 3 & 3.382 & & & & & & & & & $\mathrm{X}$ & & & & \\
\hline Umbria Marche & 26.09 .1997 & $5.7 \mathrm{Mw}$ & 3 & 3.382 & & & & & & & $\mathrm{X}$ & $\mathrm{X}$ & $\mathrm{X}$ & & & & \\
\hline
\end{tabular}

Figure 16: Main characteristics of the selected records and their distribution in the different sets of the twelve recordings each (as = aftershock).

corner period for the plateau $\left(T_{\mathrm{C}}\right)$. For EC8 soil class $\mathrm{D}$ with $T_{\mathrm{C}}=0.8 \mathrm{~s}$, the $\mathrm{N} 2$ method provides accurate results for values between $R=3.25$ and $R=3.75$. Moreover, the accuracy range is shifted down for short values of $T_{\mathrm{C}}$. For EC8 soil class A with $T_{\mathrm{C}}=0.4 \mathrm{~s}$, the $\mathrm{N} 2$ method is accurate for strength reduction factors between $R=2.5$ and $R=3$.
Fortunately, the optimized N2 method is generally accurate, regardless of the values of strength reduction factor and upper corner period for the plateau $\left(T_{\mathrm{C}}\right)$. The accuracy domain of the Lin and Miranda method is not easily determined; this method tends to be accurate for small values of strength reduction factors up to $R=2.5$. As a 
consequence, the simplified version of the N2 method leads to significant overestimations of the displacement demand for strength reduction factors smaller than 2.5 and to significant underestimations for strength reduction factors exceeding 4. For small values of the strength reduction factor $(R \leq 2.5)$, the optimized N2 method and the Lin and Miranda method result in accurate displacement demand predictions.

Accuracy of displacement demand predictions also depends on the shape of the response spectrum after the plateau. A gently decreasing branch after the plateau considerably reduces accuracy. Although this finding needs to be investigated in more detail in future studies, preliminary results suggest a threshold value of the exponent of the decreasing branch after the plateau. In order to ensure a similar extent of the accuracy domain rather than for EC8 response spectrum, a threshold value of 0.75 for the exponent of the decreasing branch $\left(1 / T^{\alpha}\right)$ after the plateau is proposed. A value slightly larger than one for the exponent of the declining branch after the plateau is not problematic since it does not significantly affect the accuracy domain of the methods. This issue should be considered for the ongoing developments of EC8.

\section{Appendix}

The main characteristics of the selected earthquakes and their distribution in the different sets of 12 recorded earthquakes each involved in the study are summarized in the table of Figure 16.

\section{Data Availability}

The data used to support the findings of this study are available from ResearchGate (DOI: 10.13140/RG.2.2.23337. 54883 ) and from the corresponding author upon request.

\section{Disclosure}

This research is based on a collaborative research project achieved with the specialized engineering company Résonance Ingénieurs-Conseils SA, Carouge, Switzerland. The investigations were achieved within the framework of an internal research project and were performed as part of the employment of both authors.

\section{Conflicts of Interest}

The authors declare that they have no conflicts of interest.

\section{References}

[1] CEN (Comité Européen de Normalisation), Eurocode 8: Design Provisions for Earthquake Resistance of Structures-Part 1: General Rules, Seismic Actions and Rules for Buildings, EN 1998-1:2004, CEN, Brussels, Belgium, 2004.

[2] L. Diana, A. Manno, P. Lestuzzi, S. Podestà, and C. Luchini, "Impact of displacement demand reliability for seismic vulnerability assessment at an urban scale," Soil Dynamics and Earthquake Engineering, vol. 112, pp. 35-52, 2018.
[3] R. Riddell, P. Hidalgo, and E. Cruz, "Response modification factors for earthquake resistant design of short period buildings," Earthquake Spectra, vol. 5, no. 3, pp. 571-590, 1989.

[4] T. Vidic, P. Fajfar, and M. Fischinger, "Consistent inelastic design spectra: strength and displacement," Earthquake Engineering \& Structural Dynamics, vol. 23, no. 5, pp. 507-521, 1994.

[5] Y.-Y. Lin and E. Miranda, "Evaluation of equivalent linear methods for estimating target displacements of existing structures," Engineering Structures, vol. 31, no. 12, pp. 30803089, 2009.

[6] M. J. Kowalsky, "Displacement-based design-a methodology for seismic design applied to RC bridge columns," Master's thesis, University of California at San Diego, La Jolla, CA, USA, 1994.

[7] Applied Technology Council (ATC), Improvement of Nonlinear Static Seismic Analysis Procedures: FEMA-440, ATC, Redwood City, CA, USA, 2005.

[8] P. Fajfar, "A nonlinear analysis method for performancebased seismic design," Earthquake Spectra, vol. 16, no. 3, pp. 573-592, 2000.

[9] H. Norda and C. Butenweg, "Möglichkeiten und grenzen der anwendbarkeit statisch nichtlinearer verfahren nach DIN EN 1998-1," Bauingenieur, vol. 86, pp. 13-21, 2011, in German.

[10] C. Michel, P. Lestuzzi, and C. Lacave, "Simplified non-linear seismic displacement demand prediction for low period structures," Bulletin of Earthquake Engineering, vol. 12, no. 4, pp. 1563-1581, 2014.

[11] L. Diana, A. Manno, and P. Lestuzzi, "Seismic displacement demand prediction in non-linear domain: optimization of the N2 method," Earthquake Engineering and Engineering Vibration, vol. 18, no. 1, pp. 141-158, 2019.

[12] A. Veletsos and N. Newmark, "Effect of inelastic behavior on the response of simple systems to earthquake motion," in Proceedings of the 2nd World Conference on Earthquake Engineering, vol. 2, pp. 895-912, Tokyo, Japan, July 1960.

[13] P. Lestuzzi and M. Badoux, "An experimental confirmation of the equal displacement rule for RC structural walls," in Proceedings of the Fib-Symposium: Concrete Structures in Seismic Regions, Paper $n^{\circ}$ 127, Athens, Greece, May 2003.

[14] F. Graziotti, A. Penna, E. Bossi, and G. Magenes, "Evaluation of displacement demand for unreinforced masonry buildings by equivalent SDOF systems," in Proceedings of the 9th International Conference on Structural Dynamics, EURODYN 2014, A. Cunha, E. Caetano, and G. Muller, Eds., , Porto, Portugal, June 2014.

[15] W. D. Iwan, "Estimating inelastic response spectra from elastic spectra," Earthquake Engineering \& Structural Dynamics, vol. 8, no. 4, pp. 375-388, 1980.

[16] E. Miranda and J. Ruiz-García, "Evaluation of approximate methods to estimate maximum inelastic displacement demands," Earthquake Engineering \& Structural Dynamics, vol. 31, no. 3, pp. 539-560, 2002.

[17] T. J. Sullivan, G. M. Calvi, and N. Priestley, "Initial stiffness versus secant stiffness in displacement-based design," in Proceedings of the 13th World Conference of Earthquake Engineering (WCEE), vol. 2888, Vancouver, Canada, August 2004.

[18] Y.-Y. Lin and E. Miranda, "Noniterative equivalent linear method for evaluation of existing structures," Journal of Structural Engineering, vol. 134, no. 11, pp. 1685-1695, 2008.

[19] N. Ambraseys, P. Smit, R. Sigbjornsson, P. Suhadolc, and B. Margaris, Internet Site for European Strong-Motion Data, 
European Commission, Research Directorate General, Environment and Climate Program, Brussels, Belgium, 2002.

[20] P. Lestuzzi and M. Badoux, Evaluation Parasismique des Constructions Existantes, Presses Polytechniques et Universitaires Romandes, Lausanne, Switzerland, in French, 2013.

[21] CREALP, Centre de Recherche sur l'Environnement Alpin, 2019, http://www.crealp.ch.

[22] N. A. Abrahamson, "Non-stationary spectral matching," Seismological Research Letters, vol. 63, no. 1, p. 30, 1992.

[23] P. Schwab and P. Lestuzzi, "Assessment of the seismic nonlinear behavior of ductile wall structures due to synthetic earthquakes," Bulletin of Earthquake Engineering, vol. 5, no. 1, pp. 67-84, 2007.

[24] P. Lestuzzi, H. Charif, S. Rossier, M. Ferrière and, and J.-P. Person, "Nonlinear time-history analysis for validation of the displacement-based seismic assessment of the RC upper bridge of a dam," Advances in Civil Engineering, vol. 2018, Article ID 9879101, 13 pages, 2018.

[25] M. Saiidi and M. A. Sozen, "Simple nonlinear seismic analysis of R/C structures," Journal of the Structural Division, vol. 107, no. 5, pp. 937-953, 1981.

[26] P. Lestuzzi and M. Badoux, "The gamma model: a simple hysteretic model for RC walls," in Proceedings of the FibSymposium: Concrete Structures in Seismic Regions, Paper $n^{\circ}$ 126, Athens, Greece, May 2003.

[27] T. Takeda, M. A. Sozen, and N. N. Nielsen, "Reinforced concrete response to simulated earthquakes," Journal of the Structural Division ASCE, vol. 96, pp. 2557-2573, 1970.

[28] S. Otani, "Inelastic analysis of R/C frame structures," Journal of the Structural Division, vol. 100, no. 7, pp. 1433-1449, 1974.

[29] R. W. Litton, A contribution to the analysis of concrete structures under cyclic loading, Ph.D. thesis, Civil Engineering Department, University of California, Berkeley, CA, USA, 1975.

[30] R. Allahabadi and G. H. Powell, "Drain-2DX user guide," Report No. UCB/EERC-88/06, College of Engineering, University of California, Berkeley, CA, USA, 1988.

[31] P. Lestuzzi, Y. Belmouden, and M. Trueb, "Non-linear seismic behavior of structures with limited hysteretic energy dissipation capacity," Bulletin of Earthquake Engineering, vol. 5, no. 4 , pp. 549-569, 2007. 


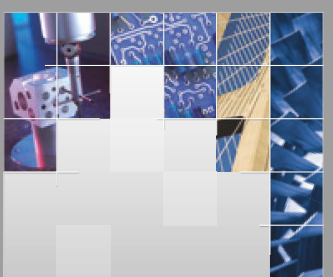

\section{Enfincering}
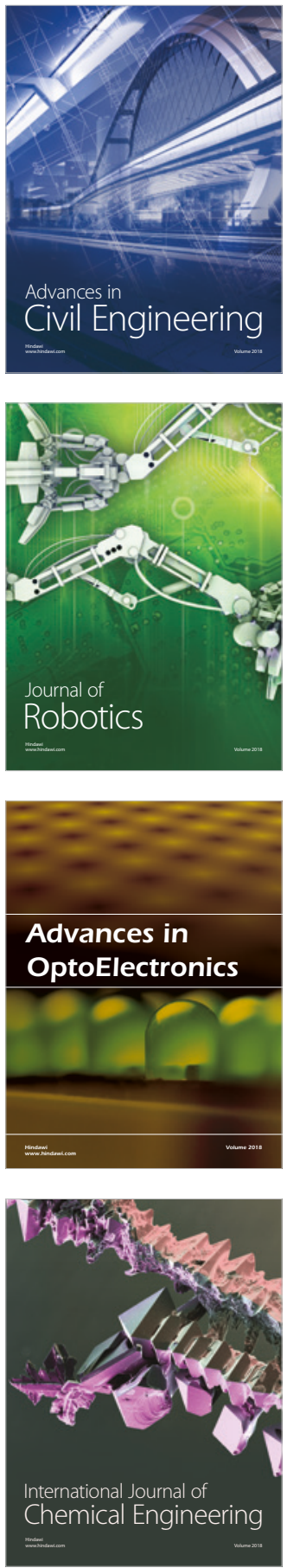

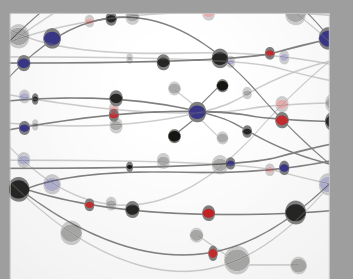

\section{Rotating \\ Machinery}

The Scientific World Journal

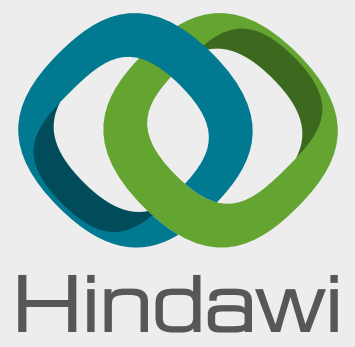

Submit your manuscripts at

www.hindawi.com
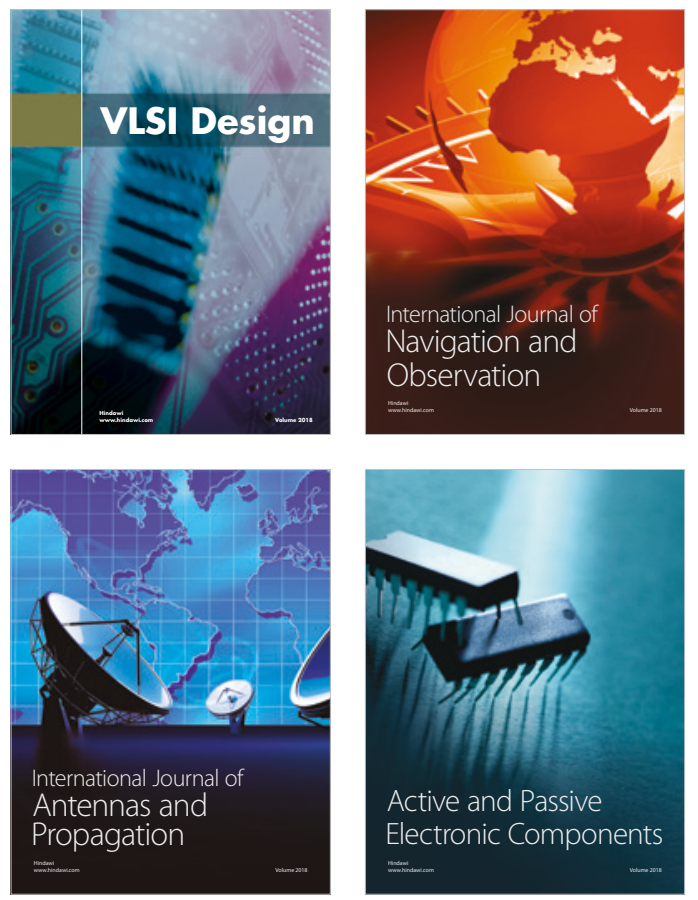
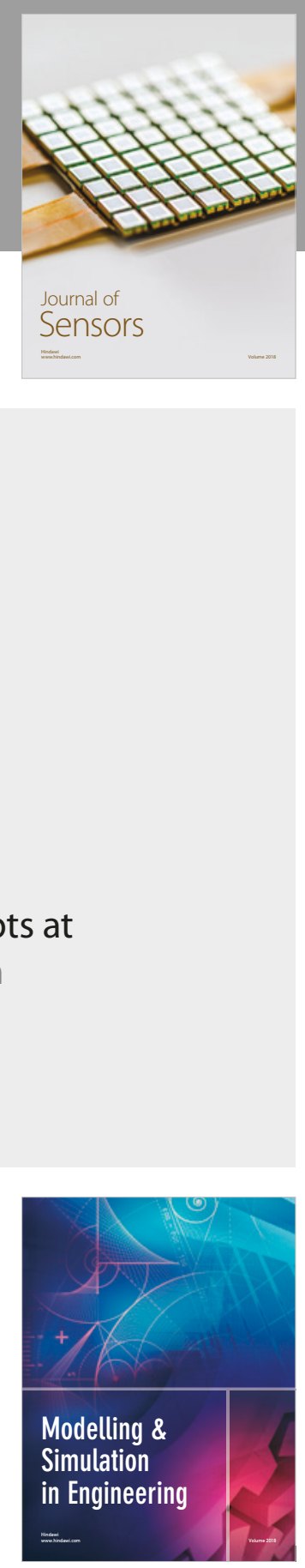

\section{Advances \\ Multimedia}
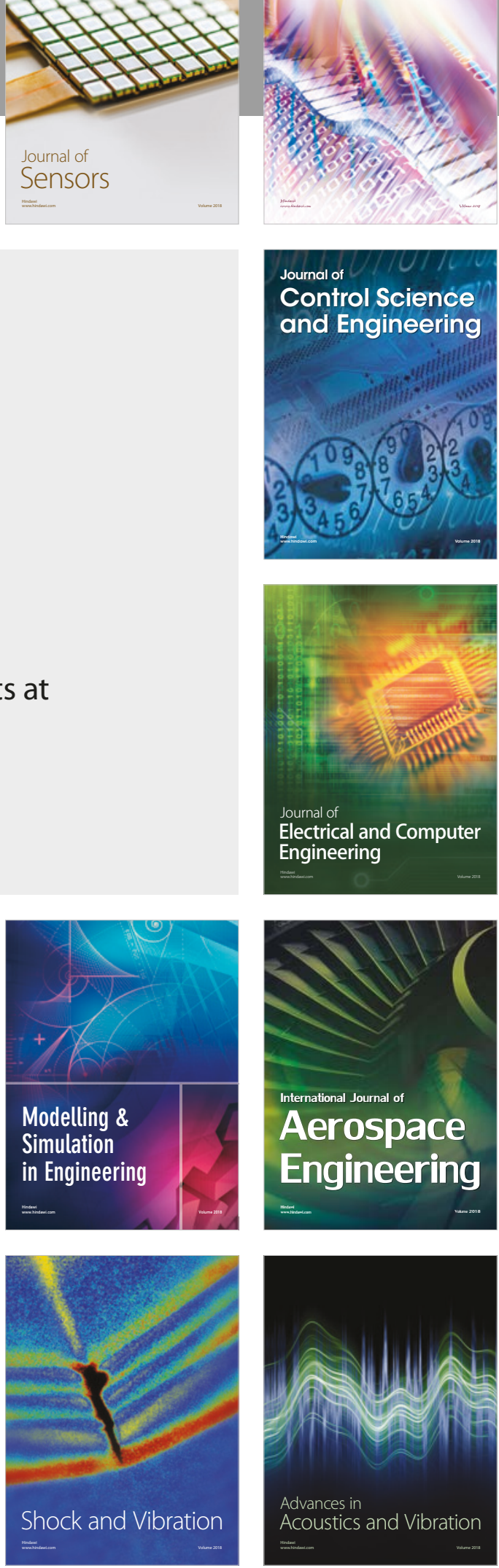